\title{
Live Imaging of Endogenous PSD-95 Using ENABLED: A Conditional Strategy to Fluorescently Label Endogenous Proteins
}

\author{
Dale A. Fortin, ${ }^{1}$ Shane E. Tillo, ${ }^{1}$ Guang Yang, ${ }^{1}$ Jong-Cheol Rah, ${ }^{2}$ Joshua B. Melander, ${ }^{1}$ Suxia Bai, ${ }^{2}$ Omar Soler-Cedeño, ${ }^{3}$ \\ Maozhen Qin, ${ }^{1}$ DBoris V. Zemelman, ${ }^{4}$ Caiying Guo, ${ }^{2}$ (DTianyi Mao, ${ }^{1}$ and ${ }^{D}$ Haining Zhong ${ }^{1,2}$ \\ ${ }^{1}$ Vollum Institute, Oregon Health and Science University, Portland, Oregon 97239, ${ }^{2}$ Howard Hughes Medical Institute, Janelia Farms Research Campus, \\ Ashburn, Virginia 20147, ${ }^{3}$ Department of Pharmacology and Physiology, Ponce School of Medicine, Ponce, Puerto Rico, 00716, and ${ }^{4}$ Center for Learning \\ and Memory, The University of Texas at Austin, Austin, Texas 78712
}

Stoichiometric labeling of endogenous synaptic proteins for high-contrast live-cell imaging in brain tissue remains challenging. Here, we describe a conditional mouse genetic strategy termed endogenous labeling via exon duplication (ENABLED), which can be used to fluorescently label endogenous proteins with near ideal properties in all neurons, a sparse subset of neurons, or specific neuronal subtypes. We used this method to label the postsynaptic density protein PSD-95 with mVenus without overexpression side effects. We demonstrated that mVenus-tagged PSD-95 is functionally equivalent to wild-type PSD-95 and that PSD-95 is present in nearly all dendritic spines in CA1 neurons. Within spines, while PSD-95 exhibited low mobility under basal conditions, its levels could be regulated by chronic changes in neuronal activity. Notably, labeled PSD-95 also allowed us to visualize and unambiguously examine otherwiseunidentifiable excitatory shaft synapses in aspiny neurons, such as parvalbumin-positive interneurons and dopaminergic neurons. Our results demonstrate that the ENABLED strategy provides a valuable new approach to study the dynamics of endogenous synaptic proteins in vivo.

Key words: cell-type-specific labeling; conditional knock-in; live imaging; protein labeling; PSD-95; sparse labeling

\section{Introduction}

Fluorescence imaging of synaptic proteins in space and time is a primary approach to investigate how these proteins contribute to both normal and abnormal brain function. Such an approach relies on the proper and specific introduction of fluorescent labels. However, current protein-labeling methods suffer from significant limitations.

Immunolabeling is typically incompatible with live imaging due to the requirements of fixation and permeabilization, and does not provide cell-specific contrast. Therefore, the primary approach for visualizing protein dynamics has been tagging a

Received Sept. 18, 2014; revised 0ct. 29, 2014; accepted 0ct. 30, 2014.

Author contributions: D.A.F., S.E.T., C.G., T.M., and H.Z. designed research;D.A.F., S.E.T., G.Y.,J.-C.R., J.B.M., S.B., M.Q., C.G., T.M., and H.Z. performed research; B.V.Z. contributed unpublished reagents/analytic tools; D.A.F., S.E.T., G.Y., O.S.-C., and H.Z. analyzed data; D.A.F., S.E.T., T.M., and H.Z. wrote the paper.

This work was supported by an NIH Director's New Innovator Award (DP20D008425), an R21 Grant (R21NS084315), and HHMI. We thank Drs Kogo Takamiya and Thomas Sudhof for their advice in designing the strategy; Drs Eric Betzig and Karel Svoboda for their support in generating and characterizing the mouse lines; Drs Daniel Lioy and Gail Mandel for sharing the Cre-expressing AAV9 virus; Drs Wolfhard Almers, John Williams and Eric Schnell for their helpful comments; and Dr Genglin Li for contributing to preliminary characterizations of the mouse lines.

The authors declare no competing financial interests.

Correspondence should be addressed to either Dr Haining Zhong or Dr Tianyi Mao, Vollum Institute, Oregon Health and Science University, 3181 Southwest Sam Jackson Park Road, L474, Portland, OR 97239. E-mail: zhong@ohsu.edu ormao@ohsu.edu.

J.-C. Rah's present address: Korea Brain Research Institute, Daegu 701-300, Korea.

DOI:10.1523/JNEUROSCI.3888-14.2014

Copyright $\odot 2014$ the authors $\quad 0270-6474 / 14 / 3416698-15 \$ 15.00 / 0$ target protein with fluorescent proteins (FPs; Chalfie et al., 1994; Cubitt et al., 1995). However, FP-tagged proteins are commonly overexpressed, which can result in undesirable side effects (Rak et al., 2003; Wagner et al., 2006; Prelich, 2012). For example, overexpression of FP-tagged PSD-95, which is a critical excitatory postsynaptic density (PSD) protein (Kim and Sheng, 2004), increases the number and size of dendritic spines, alters presynaptic release, increases frequency and amplitude of miniature EPSCs (mEPSCs), and impairs synaptic plasticity (El-Husseini et al., 2000; Béique and Andrade, 2003; Stein et al., 2003; Ehrlich and Malinow, 2004; Futai et al., 2007; Zhang and Lisman, 2010). Although knock-in of FP tags may overcome problems associated with overexpression, it is rarely done because standard knock-in strategies lead to the global expression of the FP, resulting in poor imaging contrast and lack of cell-type-specific labeling (Herzog et al., 2011).

An ideal protein-labeling method should be highly specific, stoichiometric, compatible with live cell imaging, and result in minimal perturbations to protein dynamics and cellular function. It should also follow changes in protein expression imposed by native transcriptional and translational regulations. Furthermore, the approach should be amendable to labeling a target protein in either all cells that normally express the protein, a sparse subset of cells when high-contrast imaging is required, or defined cell populations for cell-type-specific analyses.

We have developed a conditional mouse genetic strategy termed endogenous labeling via exon duplication (ENABLED). 
This strategy can be used to fluorescently tag endogenous proteins at their C-termini in a Cre recombinase-dependent manner while satisfying most of the aforementioned characteristics for an ideal protein labeling method. As a proof of principle, we used the ENABLED strategy to specifically and stoichiometrically label endogenous PSD-95 with the monomeric yellow FP mVenus (Nagai et al., 2002) in global, sparse, and cell-type-specific manners. Extensive characterizations demonstrate that PSD-95 ${ }^{\text {mVenus }}$ can functionally replace wild-type PSD-95. We determined the distribution and dynamics of endogenous PSD-95 in CA1 pyramidal neurons under basal and activity manipulated conditions. Furthermore, by specifically labeling PSD-95 in discrete population of aspiny neurons, we unambiguously identified and examined the function of morphologically unidentifiable shaft synapses in live tissue. The PSD-95-ENABLED mouse line may therefore open novel research avenues for studying excitatory shaft synapses. The ENABLED strategy should be applicable to a wide variety of important proteins that are compatible with C-terminal FP-tagging.

\section{Materials and Methods}

Animal use and procedures. All animal care, use, surgery, and euthanasia were in accordance with the animal care and use guidelines of the National Institutes of Health and were approved by the institutional animal care and use committee of the Oregon Health and Science University.

Generation of PSD-95-ENABLED and PSD-95-CreNABLED mice. The targeting construct was produced using recombineering techniques (Liu et al., 2003). A 12,892 bp genomic DNA fragment containing exons 12-20 of the PSD-95 gene was retrieved from BAC clone RP23-316E4. A loxP sequence was inserted 375 bp upstream of exon 19, and an FRTPGK-Neo-FRT-loxP cassette was inserted after the $3^{\prime}$ UTR. Thus, a fragment of 1705 bp genomic DNA containing 375 bp intron 18, exons 19-20 was floxed. The floxed fragment was repeated after the second loxP with an mVenus fusion with the coding region of exon 20 through a 12 bp linker (CCGGTCGCCACC). An FLP/FRT-dependent excision would remove the Neo cassette, whereas Cre-dependent excision would remove the floxed exon 19 and 20 to express a PSD-95 ${ }^{\text {mVenus }}$ fusion protein under native transcriptional and translational controls. The homologous arms of the construct were $3364 \mathrm{bp}$ and $8648 \mathrm{bp}$, respectively. The sequence of the targeting construct is available upon requests.

The targeting vector was electroporated into G1 ES cells which were derived from F1 hybrid blastocyst of 129 S6 $\times$ C57BL/6J. G418 resistant ES colonies were isolated and screened by nested PCR using primers outside the construct paired with primers inside the first loxP site for $5^{\prime}$ arm and mVenus for $3^{\prime} \mathrm{arm}$. The primer sequences were as follows:

$5^{\prime}$ arm forward primers: PSD Scr F1 (5'-TTGAGTCTTCCTCCAGCTTG-3') and PSD-95 Scr F2 (5'-TAGGGATTGAATCCAGG GCT- $\left.3^{\prime}\right)$; reverse primers: loxP Scr R1 (5'-GAGGGACCTAATA ACTTCGT-3') and loxP Scr R2 (5'-ATGATCGGAATTGGGCTGCA3'); 3' arm forward primers: mVenus F3 (5'-GACAACCACTAC CTGAGCTA-3') and mVenus F4 (5' - CATGGACGAGCTGTACAAGT$\left.3^{\prime}\right)$; reverse primers: PSD-95 Scr R3 (5' - TTCAGAGAGGC CTGTCAGAA-3') and PSD-95 Scr R4 (5'-CCTGTGAGCTATTCAGG AAG-3').

The ES clones with both arms positive were identified and used for generating chimeric mice via aggregating the ES cells with eight-cell embryos of CD-1 strain. Correct targeting was further confirmed by homozygosity test in progenies. The Neo cassette was removed by mating the chimeras with the FLPeR homozygous female mice (Jax no. 003946). F1 pups were genotyped by PCR using primers flanking the first loxP site, FRT-loxP site, and mVenus. The primer set lox P1 (5'-CCACAGTGTT CAAAGAGCTG-3') and lox P2 (5'-TACAGATGTGCTCACGGCAA$3^{\prime}$ ) generated PCR products of $262 \mathrm{bp}$ for the wild-type allele, and $354 \mathrm{bp}$ for the floxed (ENABLED) allele. The primer set FRT P3 (5'-GTGGCTC TGAGAACTTCAGA-3') and FRT P4 (5'-GACTGACTCCCAGTTA GTTG-3') generated PCR products of $277 \mathrm{bp}$ for the floxed (ENABLED) allele. The primers for mVenus were mVenus $\mathrm{F}$ 5'-GACGTAA
ACGGCCACAAGTT-3' and mVenus R 5' - TCGATGCCCTTCAGCTC GAT-3'. After CRE excision, the conditional (CreNABLED) allele was detected by using primer set: PSD gt lox F3 5'-TCAAGGTCCCCTACCTTGAT-3'; PSD gt lox R3 5'-GAATTCAGACTGACTCCCAG-3'; PSD gt lox R4 5'-AGAACTAGTGGATCCACCTA-3'. The lengths of PCR products were $169 \mathrm{bp}(\mathrm{F} 3 / \mathrm{R} 4)$ and $339 \mathrm{bp}(\mathrm{F} 3 / \mathrm{R} 3)$ for the conditional (CreNABLED) allele, and 236 bp (F3/R3) for the wild-type allele. After the mouse lines were established, routine genotyping was performed using the PSD gt lox F3, PSD gt lox R3, and PSD gt lox R4 primer set for both the ENABLED and CreNABLED genotypes. For ENABLED mice, this primer set gave PCR product sizes of $328 \mathrm{bp}$ for the transgenic allele and $236 \mathrm{bp}$ for the wild-type allele.

Immunogold EM. Immunogold electron microscopy (EM) was performed similarly as previously described (Rah et al., 2013). PSD-95ENABLED/Ai9 double-transgenic mice were stereotaxically injected with adeno-associated virus (AAV) serotype $2 / 1$ that expresses Cre into the primary somatosensory cortex at p65. The mice were killed at 3 months by cardiac perfusion with $4 \%$ paraformaldehyde and $0.2 \%$ glutaraldehyde in $0.1 \mathrm{~m} \mathrm{Na}$-cacodylate, $\mathrm{pH}$ 7.2. Dissected brain samples were embedded in LR white before being sectioned to $70 \mathrm{~nm}$ ultrathin sections. The sections were collected on an EM grid and blocked with $1 \%$ BSA, $0.01 \%$ Triton X-100 and $0.01 \%$ Tween 20 in PBS and then stained with an anti-GFP antibody (Abcam, no. ab13970) and a gold-conjugated secondary antibody (Jackson ImmunoResearch, no. 703-215-155). Stained sections were then postfixed and stained in $0.001 \% \mathrm{OsO}_{4}$ for $1 \mathrm{~h}$ and $1 \%$ uranyl acetate for $1 \mathrm{~h}$ before being subjected to transmitting EM imaging.

Protein quantification. Littermate wild-type, heterozygous, and homozygous mice were killed at P30-P31 and brain tissue $(20-100 \mathrm{mg}$, depending on the region) of specific regions as indicated were collected. Dissected tissues were weighed and homogenized in 20 volumes of $1 \times$ Laemmli buffer using a dounce homogenizer and $>10$ strokes. Samples were heated to $90^{\circ} \mathrm{C}$ for $5 \mathrm{~min}$ and the protein contents of individual samples were quantified using the Bio-Rad RC DC protein assay kit. The samples were then kept frozen $\left(-20^{\circ} \mathrm{C}\right)$ until use. Equal amounts of lysate (30-50 $\mu \mathrm{g} / \mathrm{lane})$ were loaded onto a PAGE gel (Bio-Rad, mini gel format) and subjected to Western blotting analyses. We used the following antibodies: PSD-95, NeuroMab, no. 75-028; actin, Cell Signaling Technology, no. 3700S; GluA1, Millipore no. 05-855R; GluN1, BD PharMingen, no. 556308; synapsin, Millipore Bioscience Research Reagents, no. AB1543P; synaptophysin, Abcam, no. ab8049; PSD-93, NeuroMab, no. 75-057; SAP97, NeuroMab, no. 75-030; SAP102, NeuroMab, no. 75-058. For most proteins, the membrane was blocked with AquaBlock (EastCoast Bio) before primary antibody incubation. Fluorophore-conjugated secondary antibodies (LI-COR) were then used, and the fluorescent signals were detected using an Odyssey IR scanner (LI-COR). For NR1 and SAP97, membranes were blocked with 5\% milk and HRP-conjugated secondary antibodies (GE HealthCare) were used. Signals were detected using chemiluminescent approaches (SuperSignal, Thermo Scientific; $0.1-0.3 \times$ dilution in water) and exposed to film. The exposed films were then scanned and quantified using custom software written in MATLAB. All signals were normalized to those of loading controls ( $\beta$-actin within the same lane), and then further normalized to the signal of wild-type littermates that were run in parallel on the same gel.

cDNA preparation, $R T-P C R$, and quantitative real-time PCR. Total RNA was isolated using TRIzol reagent (Invitrogen). After treatment with RNase-free DNase I (New England Biolabs), first-strand cDNAs were synthesized with M-MLV reverse transcriptase and Oligo-dTs (Promega).

For RT-PCR shown in Figure 4, nested PCR was performed using the following primers: pair 1 (23 cycles): PSD-95 3' UTR forward: 1, 5' CCTGCCCTGGCTTGGCCTGG-3', mVenus reverse: 1, 5' -CCCTCGCCCTCGCCGGACAC-3'exon; pair 2 (23 cycles): PSD-95 3' UTR forward: 2, 5'-TGGACTCACCCTGCCTCCAC-3', mVenus reverse: 2 5'-AGCTCGACCAGGATGGGCAC-3'. The PCR products were cloned using the TA cloning kit (Invitrogen) and five clones were sequenced. All clones gave identical results.

Real-time quantitative PCR was conducted using the Bio-Rad Opticon Detection System. PCR primers used in this study were as follows: 
PSD-95 forward: 5'-AGACGGTGACGCAGATGGAA-3'; PSD-95 reverse: $5^{\prime}$-TCGGGGAACTCGGAGAGAAG-3'; $\beta$-actin forward: $5^{\prime}$ GATCATTGCTCCTCCTGAGC-3'; $\beta$-actin reverse: $5^{\prime}$-ACTCCTGCTT GCTGATCCAC-3'; To compare across samples, we analyzed the Ct value of real-time PCR data with the $\Delta \Delta \mathrm{Ct}$ method normalized to the endogenous control ( $\beta$-actin).

In utero electroporation and in utero viral injection. In utero electroporation was performed as described previously (Gray et al., 2006; Zhong et al., 2009) at E15.5 using an electroporator (CUY21, BEX) with five 100 ms pulses of $38 \mathrm{~V}$. cDNA encoding the Cre recombinase were put into a vector with a CAG promoter, an intron, and a WHP post-transcriptional response element. For in utero viral infection, $0.5-1 \mu \mathrm{l}$ of diluted AAV9 or AAV 2/1 virus that directs the expression of Cre under a CAG promoter was injected to the lateral ventricles of E15.5 mouse embryos using a surgical procedure essentially identical to that for in utero electroporation, with the omission of electroporation. The virus was diluted (typically $100-1000 \times$ ) in $1 \times$ PBS at a dilution empirically determined to achieve an optimal labeling density of neurons for imaging.

For high-contrast imaging experiments, we preferred the in utero viral infection method over in utero electroporation because it achieved a more controllable and reproducible density of labeled neurons that are relatively evenly distributed throughout the brain (Fig. 1C4,C5) and even in the spinal cord (data not shown).

DiOlistic labeling. DiOlistic bullets coated with the fluorescent lipophilic cationic indocarbocyanine dye (DiI, Invitrogen, no. D-282) were prepared as previously described (Gan et al., 2000). Briefly, $0.05 \mathrm{~g}$ of tungsten beads (1.7 $\mu \mathrm{m}$, Bio-Rad, no. 165-2269) were placed onto a glass slide. Two to $4 \mathrm{mg}$ of DiI were added to $200 \mu \mathrm{l}$ of methylene chloride (Sigma-Aldrich Diagnostics no. 17-3), and the solution was vortexed at maximum speed until all crystals were dissolved. The dissolved dye was then added to the tungsten beads. The dye-coated beads were spread across the surface of a glass slide, dried for 1-2 min, and scraped into a 15 $\mathrm{ml}$ conical tube using a clean razor blade. Three milliliters of purified water were added, and the solution was sonicated for $1-2 \mathrm{~min}$. The tungsten beads were then drawn up into the Tefzel tubing using a syringe while being vortexed. The tubing was placed onto a tubing preparation station (Bio-Rad, no. 165-2418), rotated three to four times, and allowed to sit undisturbed for an additional 2-3 min before being rotated again three to four times. The water was withdrawn from the tubing. The tubing was allowed to dry for $5 \mathrm{~min}$ in the presence of nitrogen $(0.5$ $\mathrm{L} / \mathrm{min}$ ), and then cut into 0.5 inch bullets using a tubing cutter. The bullets were stored with desiccant in foil-wrapped scintillation vials at $4^{\circ} \mathrm{C}$.

Just before shooting, acute slices fixed with 1.5\% PFA were placed individually in 12-well culture plates (Sigma-Aldrich, no. CLS3513) with $0.5 \mathrm{ml}$ of PBS. Individual bullets were placed in a gene gun cartridge and the gene gun tip was positioned over each well, maintained at a distance of $1-2 \mathrm{~cm}$ from each slice and shot at a pressure of 100-120 psi through a cell culture filter insert (Millipore, no. PICM03050). DiOlistically labeled slices were stored at $4^{\circ} \mathrm{C}$ for $72 \mathrm{~h}$ to allow the DiI to diffuse along neuronal membranes. Slices were then fixed with $4 \%$ PFA for $1 \mathrm{~h}$ and rinsed in PBS before being mounted onto glass slides for imaging.

Organotypic slice cultures and chronic activity manipulation. Cultured hippocampal slices were prepared from P6-P7 PSD-95-ENABLED/Ai9 double-heterozygous mice that underwent in utero AAV injection to express Cre in a sparse subset of neurons and were maintained at $35^{\circ} \mathrm{C}$ $5 \% \mathrm{CO}_{2}$ as previously described (Zhong et al., 2009). Experiments were performed at $14-21 \mathrm{~d}$ in vitro. Where indicated, drugs were added to the culture medium and returned to the incubator for $1-3 \mathrm{~d}$.

Acute slice preparation. Brain slices (250-300 $\mu \mathrm{m}$ thick) were prepared from mice, typically at P14-P21, using an ice-cold cutting solution containing the following (in mM): 110 choline chloride, $25 \mathrm{NaHCO}_{3}, 25$ D-glucose, $2.5 \mathrm{KCl}, 7 \mathrm{MgCl}_{2}, 0.5 \mathrm{CaCl}_{2}, 1.25 \mathrm{NaH}_{2} \mathrm{PO}_{4}, 11.5$ sodium ascorbate, and 3 sodium pyruvate and being gassed with $95 \% \mathrm{O}_{2} / 5 \%$ $\mathrm{CO}_{2}$. For experiments involving the $P V$-IRES-Cre driver line P21-P30 mice were used because parvalbumin (PV) expression turns on relatively late during development (Nitsch et al., 1990; Bergmann et al., 1991). Brain slices were cut coronally or at the "magic angle" (Bischofberger et al., 2006) to preserve the integrity of CA1 neuronal morphology. Slices were incubated in a custom submersion-type recovery chamber in gassed artificial CSF (ACSF) containing the following (in mM): $127 \mathrm{NaCl}, 25$ $\mathrm{NaHCO}_{3}, 25 \mathrm{D}$-glucose, $2.5 \mathrm{KCl}, 1 \mathrm{MgCl}_{2}, 2 \mathrm{CaCl}_{2}$, and $1.25 \mathrm{NaH}_{2} \mathrm{PO}_{4}$ at $35^{\circ} \mathrm{C}$ for $30-45 \mathrm{~min}$ and then at room temperature for up to $6 \mathrm{~h}$. Individual slices were subsequently transferred to a recording chamber fixed to the stage of an upright microscope (Olympus BX51WIF) that was circularly perfused with freshly oxygenated saline at room temperature (RT) and allowed to acclimate for 5-10 min before the start of imaging or electrophysiological recording.

Electrophysiology. Whole-cell voltage-clamp recordings of mEPSCs from hippocampal CA1 pyramidal neurons were recorded using an Axopatch-200b amplifier (Molecular Devices) at RT. Electrophysiological signals were filtered at $2 \mathrm{kHz}$, and digitized and acquired at $10 \mathrm{kHz}$ with pClamp 9.0. The data were analyzed using Clampfit. AMPA receptor mediated mEPSCs were isolated by addition of $1 \mu \mathrm{M}$ TTX, $10 \mu \mathrm{M}$ GABAzine, and $50 \mu \mathrm{M}$ D-APV to the bath perfusate to block Na channels, GABA-A receptors, and NMDA receptors, respectively. Patch electrodes were pulled from borosilicate glass capillaries (3-5 M $\Omega$ ) using a PC-10 vertical pipette puller (Narishige). The internal pipette solution contained the following (in mM): 132 Cs-gluconate, 10 HEPES, $10 \mathrm{Na}$ phosphocreatine, $4 \mathrm{MgCl}_{2}$, $4 \mathrm{Na}_{2}$-ATP, $0.4 \mathrm{Na}$-GTP, $3 \mathrm{Na}$-Ascorbate, and 0.6 EGTA, pH $7.3\left(295 \pm 5 \mathrm{mmol} \cdot \mathrm{kg}^{-1}\right)$. Cells were held at $-70 \mathrm{mV}$ throughout the course of the experiment.

For other experiments, whole-cell voltage-clamp recordings were performed at room temperature using a Multiclamp 700B amplifier (Molecular Devices). Electrophysiological signals were filtered at $2 \mathrm{kHz}$, and then digitized and acquired at $20 \mathrm{kHz}$ with custom software written in MATLAB. The data were analyzed using either custom software written in MATLAB or predefined routines in Clampfit. To stimulate the Schaffer-collateral pathway, a bipolar tungsten-stimulating electrode was positioned in the stratum radiatum $100-150 \mu \mathrm{m}$ lateral to the recorded neuron. The stimulus intensity was adjusted to evoke EPSCs of $50-100 \mathrm{pA}$ at a holding potential of $-70 \mathrm{mV}$. For the uncaging experiment involving CA1 neurons, perforated patch recordings were used with amphotericin B $(0.5 \mathrm{mg} / \mathrm{ml})$ included in the patch solution. For recordings involving shaft synapses, a potassium-based internal was used containing the following (in mM) $130 \mathrm{~K}$-gluconate, 10 HEPES, $10 \mathrm{Na}$ phosphocreatine, $4 \mathrm{Na}_{2}$-ATP, $0.4 \mathrm{Na}-\mathrm{GTP}, 0.2 \mathrm{CaCl}$, and $1 \mathrm{EGTA}$, pH 7.3 $\left(290 \pm 5 \mathrm{mmol} \cdot \mathrm{kg}^{-1}\right)$. Cells were held at $-70 \mathrm{mV}$ unless otherwise stated. Where applicable, long-term potentiation (LTP) was induced under whole-cell configuration by delivering a single $2 \mathrm{~Hz}$ train of 120 pulses while holding the postsynaptic neuron at $0 \mathrm{mV}$.

Two-photon imaging and FRAP. We used a custom-built two-photon microscope controlled by ScanImage (Pologruto et al., 2003). Two Ti: sapphire lasers (MaiTai, Spectra Physics) were combined with polarized optics and passed through the same set of scan mirrors and objective for simultaneous imaging and uncaging/bleaching. A water-immersion objective from Olympus $(60 \times, 1.0 \mathrm{NA})$ was used. Experiments were performed at room temperature. mVenus and tdTomato fluorescence were separated using a Chroma 565dcxr dichroic mirror and isolated using HQ510/70 (Chroma) and 630/92 (Semrock) emission filters, respectively.

In vivo two-photon imaging was performed as previously described (Gray et al., 2006; Zhong et al., 2009) using a Zeiss LSM 7MP imaging system with a $20 \times, 1.05$ NA objective.

Acute brain slices were circularly perfused with gassed ACSF. For chronic imaging of cultured hippocampal slices, the slice was imaged inside the culture dish submerged with slice culture medium. The imaging laser was tuned to $960 \mathrm{~nm}$ to simultaneously excite mVenus and tdTomato. Images were taken at an $x-y$ pixel size of $0.06-0.1 \mu \mathrm{m}$, and a $z$-step size of $0.8 \mu \mathrm{m}$. The images from different color channels were individually adjusted for brightness and contrast before being combined into a single color image.

For fluorescence recovery after photobleaching (FRAP) experiments, after taking three initial baseline images every $5 \mathrm{~min}, 910 \mathrm{~nm}$ illumination was applied within a small region-of-interest (ROI; i.e., a single spine or individual PSD- $95^{\mathrm{mVenus}}$ puncta) at a power empirically determined to achieve a bleaching of $50-80 \%$ of original mVenus fluorescence. After 
A

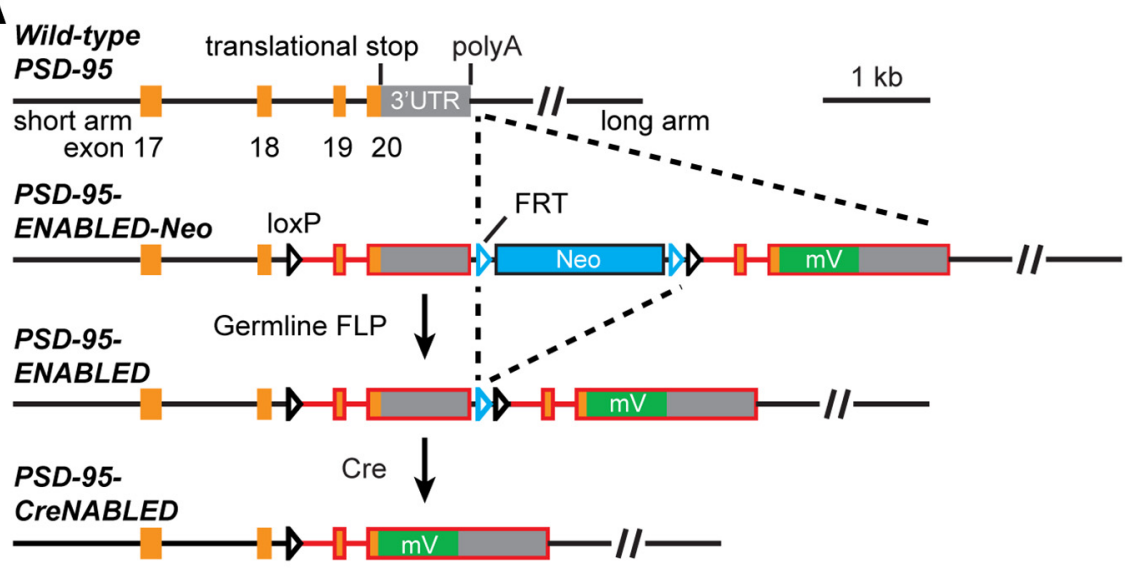

B

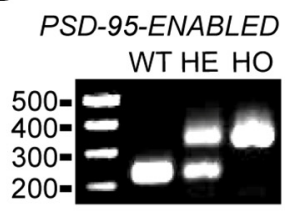

PSD-95-CreNABLED

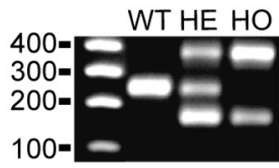

C
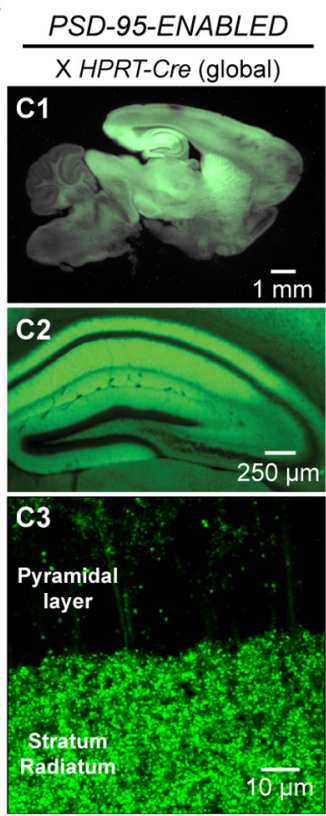

PSD-95-ENABLED / Ai9
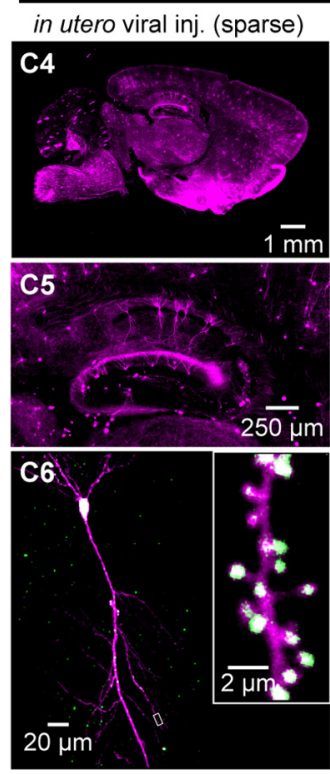

$X D A T$-Cre (cell-type specific
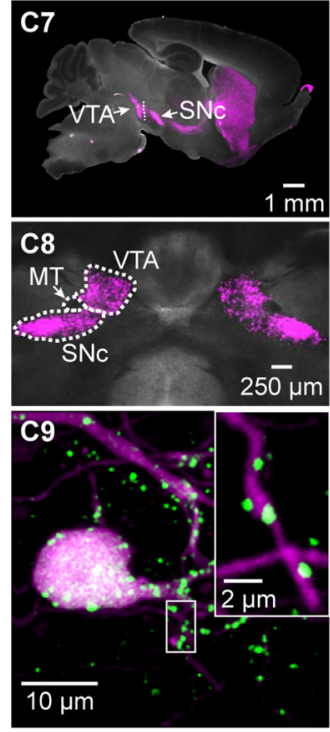

D

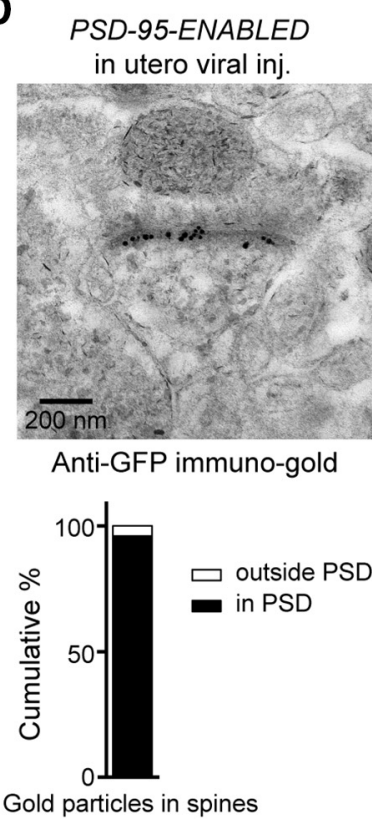

Figure 1. The ENABLED strategy to fluorescently label endogenous PSD-95. A, Schematic illustration of the genetic strategy for creating the PSD-95-ENABLED and PSD-95-CreNABLED mouse lines. The Neo cassette was removed by crossing the PSD-95-ENABLED-Neo mouse to the FLPeR mouse. Subsequent Cre recombination resulted in the PSD-95-CreNABLED genotype with PSD-95 ${ }^{\text {mVenus }}$ being expressed under endogenous transcriptional and translational controls. $\boldsymbol{B}$, Genotyping results from wild-type (WT), heterozygous (HE), and homozygous (HO) mice for PSD-95-ENABLED and PSD-95-CreENABLED mouse lines. C, Representative images of PSD-95 labeling (green) in all neurons (C1-C3), a random sparse subset (C4-C6), and specific neuronal subtypes (C7-C9; using the DAT-(re driver line). Magenta shows tdTomato signal resulting from (re-dependent recombination of the Aig allele. For $\mathbf{C}$ and $\mathbf{8}$, fluorescent images were overlaid on the corresponding wide-field images to reveal the slice morphology. Only tdTomato fluorescence is shown in $\mathbf{C}, \mathbf{C 5}, \mathbf{C}$, and $\mathbf{C} \mathbf{8}$ because under a macroscope, the autofluorescence of fixed samples overwhelmed the green PSD-95 ${ }^{\text {mVenus }}$ fluorescence in sparsely labeled samples. Note that in $\mathbf{8}$, neurons in VTA and SNc but not the adjacent medial terminal nucleus (MT) were labeled. $\boldsymbol{D}$, Representative image and quantification of immunogold EM using an anti-GFP antibody (Abcam, no. ab13970). Data were analyzed from 19 spines in five independent fields-of-view on ultrathin sections prepared from a mouse brain.

bleaching, images were acquired every 5 or $15 \mathrm{~min}$. Only the $15 \mathrm{~min}$ time points are shown.

Image analyses were performed using custom software written in MATLAB. ROIs were drawn manually on the $x-y$ max projection images. The green $(G)$ and red $(R)$ signals within each ROI were then integrated after background subtraction (from a manually selected background ROI) for three consecutive $z$-slices $(0.8 \mu \mathrm{m} z$-steps $)$ with the middle $z$-slice yielding the highest integrated value in red among all $z$-slices. A small amount of bleedthrough from tdTomato fluorescence into the green channel ( $\sim 3-4 \%$ depending on the setup) was corrected in calculations. Bleaching due to repeated imaging throughout the course of an individual experiment was observed in neighboring control ROIs and was therefore corrected by fitting with a single exponential function.

Some CreNABLED neurons exhibited a low level of PSD-95 ${ }^{\text {mVenus }}$ throughout the neuron, presumably because the Cre-recombination event took place relatively late during development and PSD-95 ${ }^{\text {mVenus }}$ has not completely replaced untagged PSD-95. To ensure a sufficient level of signal-to-noise ratio in the experiment for determining the PSD-95 and spine volume relationship, only neurons with their brightest half of spines exhibiting a green to red ratio of $>0.1(\sim 3 \times$ above the detection threshold) were analyzed.

Glutamate uncaging. For glutamate uncaging, $2.4 \mathrm{~mm}$ MNI-caged-Lglutamate (Tocris Bioscience) and $1 \mu \mathrm{M}$ TTX were added to ACSF. Glutamate uncaging was induced by applying $50-80 \mathrm{~mW}$ (measured at the back focal plane of the objective) light pulses of $0.2-0.5$ ms duration 720 $\mathrm{nm}$ light. Approximately $20 \%$ of the power was transmitted through the objective. The power was held constant within the same field of view but was changed depending on tissue depth. The uncaging depth in the slice was restricted to $10-80 \mu \mathrm{m}$ from the surface of the tissue. Uncagingevoked EPSCs (uEPSCs) were isolated by the addition of $10 \mu \mathrm{M}$ GABAzine and $5 \mu \mathrm{M}$ CPP to the bath perfusate to block GABA-A and NMDA receptors, respectively. uEPSCs were then induced by positioning the 
A

A1

A2

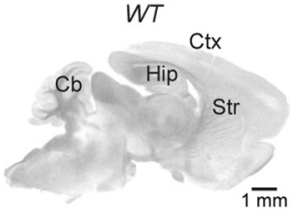

ENABLED (het)

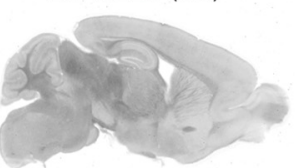

A3

Global CreNABLED (het)

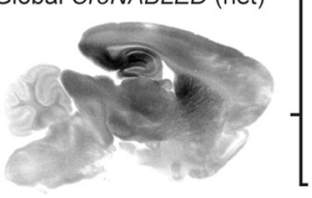

D

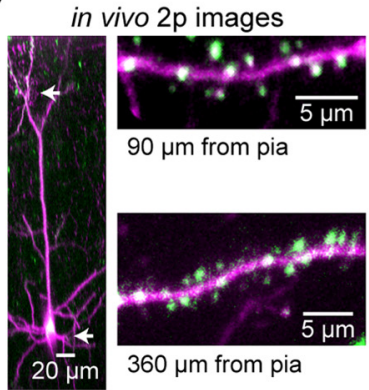

B

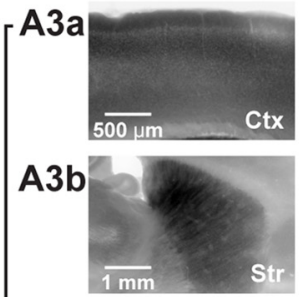

A3c

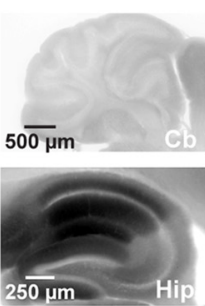

C

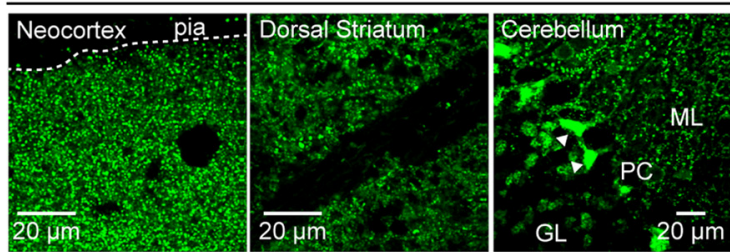

parse CreNABLED in PSD-95-ENABLED/Ai9 background
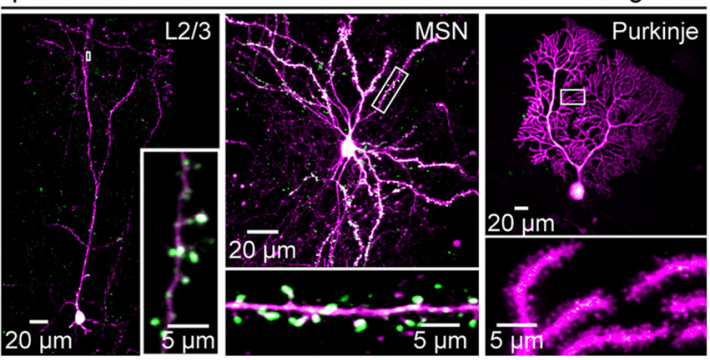

E

Sparse CreNABLED in PSD-95-ENABLED/Ai9 background
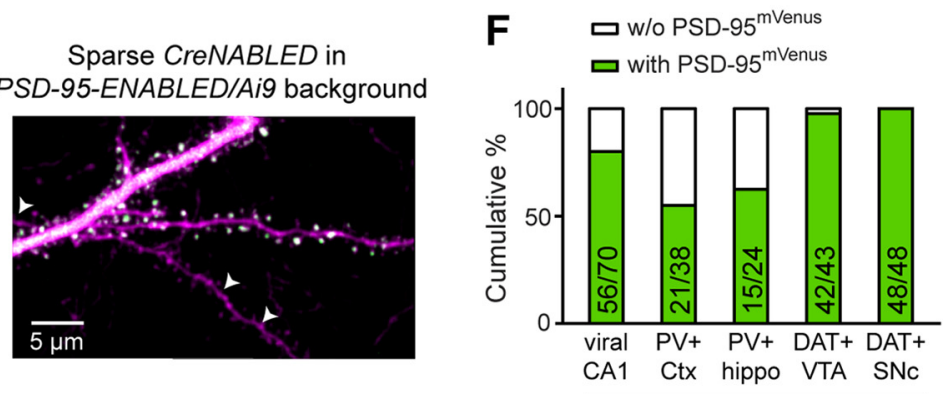

tdTomato expressing neurons

Figure 2. PSD-95 ${ }^{\text {mVenus }}$ expression in global and sparse CreNABLED brain slices. $\boldsymbol{A}$, Macroscopic images of sagittal brain sections of the indicated genotypes. Green fluorescence is shown in grayscale. Zoom-in images for the global CreNABLED brain section are shown to the right ( $A 3 \mathbf{a}-\boldsymbol{A} \mathbf{d} \boldsymbol{d})$. $\boldsymbol{B}$, Two-photon images from global PSD-95-CreNABLED mice. GL, Granule cell layer; PC, Purkinje cell layer; ML, molecular layer. Arrowheads indicate the pinceau structures. C, Representative two-photon images from acute brain slices prepared from PSD-95-ENALBED/Ai9 double-heterozygous mice that were in utero viral injected to express Cre in a sparse subset of neurons. L2/3, Cortical layer 2/3 pyramidal neuron, $n=8$ mice; MSN, medium spiny neuron, $n=5$; Purkinje, $n=6$. Note that the low levels of green signal observed in neuronal soma and dendrites of the Purkinje neuron were due to bleedthrough from tdTomato because we made the contrast for green very high to see any possible mVenus fluorescence within individual spines. $\boldsymbol{D}$, In vivo two-photon image of sparely labeled layer $2 / 3$ pyramidal neuron. A side view of the imaged neuron and top views of the zoom-in dendrites are shown. Arrows indicate the approximate position where the zoom-in images were taken. $\boldsymbol{E}$, A representative two-photon image from an acute brain slice showing two tdTomato positive dendrites in the stratum radiatum of the hippocampal CA1 region, one being positive for PSD-95 ${ }^{\text {menus }}$, whereas the other was negative (arrows). $\boldsymbol{F}$, The percentage of tdTomato positive neurons that were also positive for PSD-95 ${ }^{\mathrm{mVenus}}$. The brain region and neuronal types are indicated. Cre was introduced using either in utero viral infection or by crossing to the indicated Cre driver line. The quantification was done at P14-P21 for viral infected animals and at P30 for PV and dopaminergic neurons. Also, note that we rarely see systematic PSD-95 ${ }^{\text {mVenus }}$ fluorescence puncta outlining the shape of a dendrite or a neuron without tdTomato fluorescence, suggesting that nearly all PSD-95 ${ }^{\text {mVenus }}$-positive neurons are also tdTomato-positive. Ctx, Cortex; hippo, hippocampus.

uncaging beam either at the tip of chosen spines or just adjacent to identified PSD-95 ${ }^{\mathrm{mVenus}}$ puncta. uEPSCs amplitudes were measured by averaging 5-10 trials per position elicited at a frequency of $0.1 \mathrm{~Hz}$. Peak uEPSC amplitude was calculated as the difference between the mean current amplitude over a $2 \mathrm{~ms}$ window around the peak and the mean current amplitude over a $25 \mathrm{~ms}$ window before the uncaging stimulus. In some experiments, $10 \mu \mathrm{M}$ NBQX was added at the end of the experiment to confirm that uEPSCs were mediated by AMPA receptors.

Data analysis. Averaged data are presented as mean \pm SEM unless noted otherwise. $n$ indicates the number of experiments. $p$ values were obtained from $t$ tests, unless noted otherwise. The significance level $\alpha=$ 0.05 with Bonferroni correction for the number of tests.

\section{Results}

Design of the ENABLED strategy and generation of PSD-95-ENABLED mice

To achieve conditional labeling of endogenous proteins at their C-termini, we duplicated the last coding exon(s) of a target gene, including the 3' UTR, and its adjacent sequence (Fig. 1A). The endogenous copy of the exon was flanked by Cre recognition (loxP) sites and the FP sequence was fused to the C-terminus of the coding sequence in the duplicated exon. For most mammalian genes, the last coding exon and adjacent sequences contain both the translational stop codon and the polyadenylation signal, which defines the end of an mRNA. As a result, the duplicated exon containing the FP tag was not expected to be expressed without Cre. However, in cells expressing Cre, the endogenous untagged exon is excised, leaving the FP-tagged exon to be expressed under native transcriptional and translational controls. We termed the genotype before Cre recombination "ENABLED" and that after Cre recombination "CreNABLED."

We used the above strategy to label PSD-95 with the bright and rapid-folding FP mVenus (Griesbeck et al., 2001; Nagai et al., 2002; Fig. 1). PSD-95 has been C-terminally tagged by GFP in many studies, albeit via overexpression; and the interaction of PSD-95-GFP with other synaptic proteins appeared normal (Zhang et al., 2009). Because the intron between the last two exons of PSD-95 (exon 19 and 20) were short (221 bp), both exons, including the 3 ' UTR, were duplicated and inserted downstream of the polyadenylation signal (Fig. 1A; see Materials and 
A
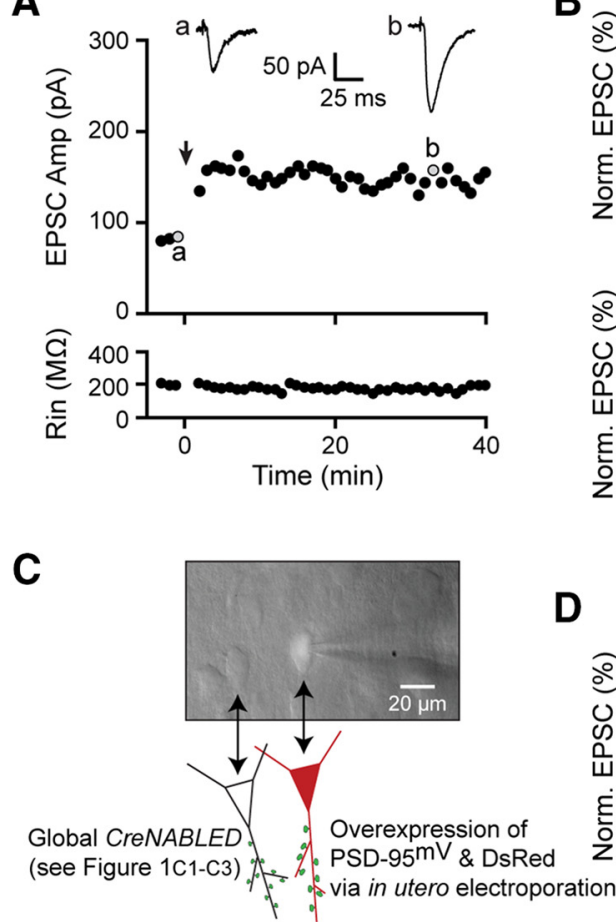

B
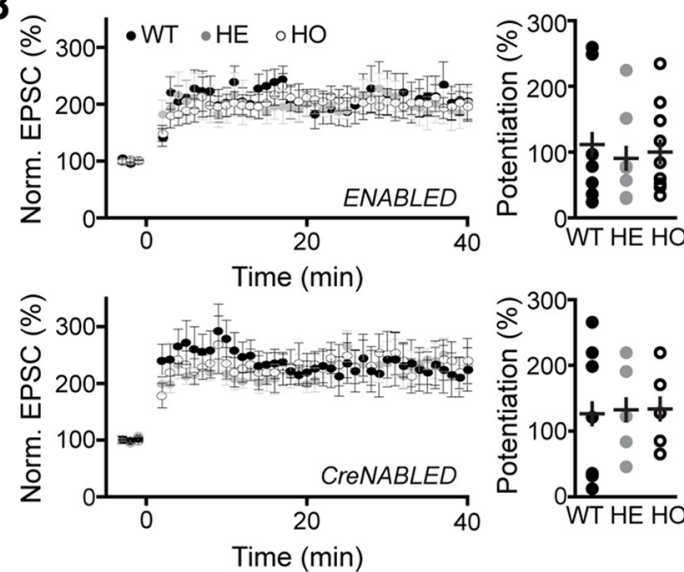

Time $(\min )$

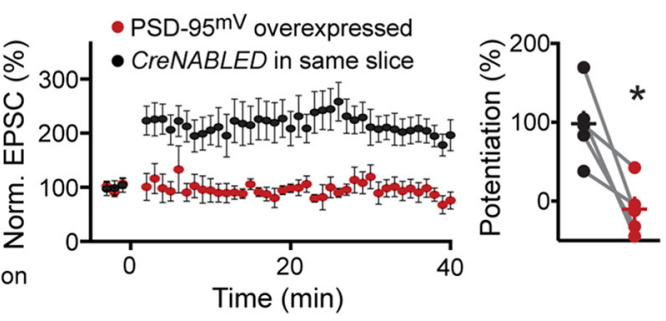

Figure 3. PSD-95-ENABLED and CreENABLED mice expressed normal LTP. A, Representative LTP experiment performed on a CA1 pyramidal neuron from a heterozygous PSD-95CreNABLED mouse. LTP was induced using a pairing protocol (arrow). EPSC amplitudes and input resistances $(R m)$ are shown. Inset shows individual current traces before and after LTP induction indicated by the gray filled circles. $\boldsymbol{B}$, Left, averaged LTP data for the indicated genotypes. Right, the percentage potentiation above baseline (averaged over last 10 min) is shown for individual experiments. C, Illustration of the experimental design in D. PSD-95 ${ }^{\mathrm{mV} \text { enus }}$ (PSD-95 ${ }^{\mathrm{mV}}$ ) and DsRed Express were overexpressed in a sparse subset of neurons in PSD-95-CreNABLED homozygous mice using in utero electroporation. The epifluorescent DsRed Express image identifying the transfected neuron was overlaid on a Hoffman-modulated contrast image of the brain slice. Thus, the fluorescent neuron was electroporated to overexpress PSD-95 ${ }^{\mathrm{mVenus}}$. Untransfected neurons expressed PSD-95 ${ }^{\mathrm{mVenus}}$ at endogenous levels via the ENABLED strategy (i.e., global (reNABLED). D, LTP measures from paired CA1 neurons expressing PSD-95 ${ }^{\mathrm{mVenus}}$ at endogenous levels (black) or overexpressing PSD-95 ${ }^{\mathrm{mVenus}}$ (red). Adjacent neurons were recorded sequentially from the same brain slices with alternating order; $n=6$ slices from six animals. Only five pairs are shown on the right because one pair did not last all $40 \mathrm{~min}$. * indicates statistically significant.

Methods for details). We generated knock-in mice harboring this genetic modification (named PSD-95-ENABLED). The successful production of the mouse line was verified by PCR (Fig. $1 B$; see Materials and Methods) and the ability to generate homozygous progenies.

\section{Cre-dependent fluorescent labeling of PSD-95}

A major advantage of the ENABLED strategy over conventional knock-in methods is that Cre recombinase can be introduced either globally in all cells, in a sparse subset of neurons, or in specific neuronal subtypes, depending on the need of experiments. Figure $1 C$ illustrates examples of these different approaches. First, germline Cre expression by crossing to Hprt-Cre mice (Jax no. 004302) resulted in the global PSD-95CreENABLED mouse line in which Cre recombination was completed in all cells (Figs. $1 B, C 1-C 3,2 A, B$ ). This line is equivalent to a conventional knock-in of PSD-95 ${ }^{\text {venus }}$ and can be stably maintained. Second, for high-contrast imaging, we crossed PSD95-ENABLED mice with Ai9 mice (Madisen et al., 2010), and then introduced Cre using in utero injection of AAV to randomly infect a sparse subset of neurons (Figs. 1C4-C6, 2C). The Ai9 allele expresses the red cytosolic marker tdTomato upon Cre recombination. Both PSD-95 mVenus (green, from mVenus) and neuronal morphology (magenta, from tdTomato) were observed with high-contrast within the same neuron across the brain in neuronal types known to express PSD-95. In acute brain slices, PSD-95 ${ }^{\text {mVenus }}$ signals were sufficiently bright to be observable at P6 in hippocampal CA1 neurons. In adult mice $(\sim$ P60), PSD- $95^{\text {mVenus }}$ fluorescence could be detected within individual spines using in vivo two-photon imaging even at depths of $\sim 350 \mu \mathrm{m}$ below the pial surface (Fig. 2D). Third, for cell-type-specific analysis, we crossed the PSD-95-ENABLED/Ai9 mice to cell-typespecific Cre driver lines. Figure 1C7-C9 shows an example using the DAT-Cre line (Jax no. 006660), which expresses Cre within dopaminergic neurons in the ventral tegmental area (VTA) and substantia nigra pars compacta (SNc). PSD-95 mVenus puncta were evident in the soma and dendrites of labeled neurons (Fig. 1C9).

The efficacy of Cre-mediated recombination may vary depending on the genomic environment and sequence of loxP sites (Badea et al., 2009). Indeed, when in utero viral infection or Credriver lines were used, we occasionally found neurons that expressed tdTomato but not PSD-95 ${ }^{\text {mVenus }}$ (Fig. 2 E, F). Eighty, 58, and $99 \%$ of tdTomato-positive neurons also expressed detectable levels of PSD-95 ${ }^{\text {mVenus }}$ when in utero viral infection, the $P V$ IRES-Cre (Jax no. 008069), and DAT-Cre driver lines were used, respectively. This result indicates that the Cre recombination efficacy for the PSD-95-ENBLED loci, although lower, is still comparable to that of Ai9.

\section{The ENABLED strategy labels PSD-95 at the right places}

We examined whether our method of labeling endogenous PSD-95 was specific. In global PSD-95-CreNABLED mice, strong mVenus fluorescence was observed macroscopically throughout many brain regions, resembling published immunostaining patterns of PSD-95 (Hunt et al., 1996; Fukaya and Watanabe, 2000; 
A
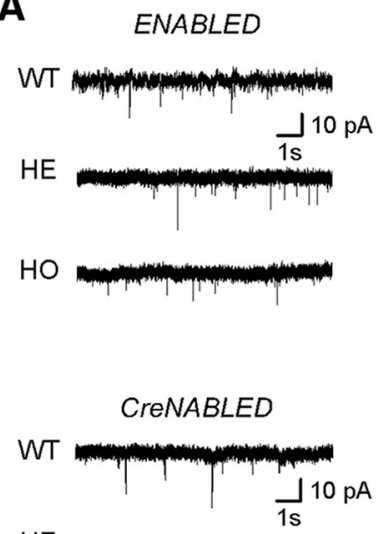

HE

HO

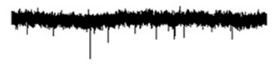

B

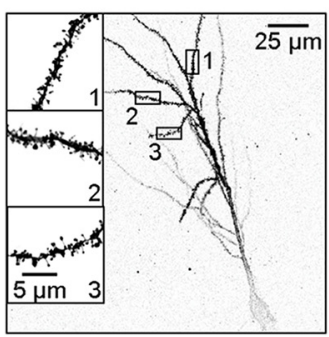

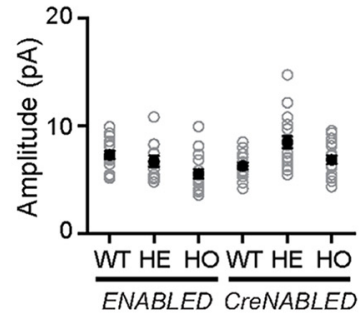
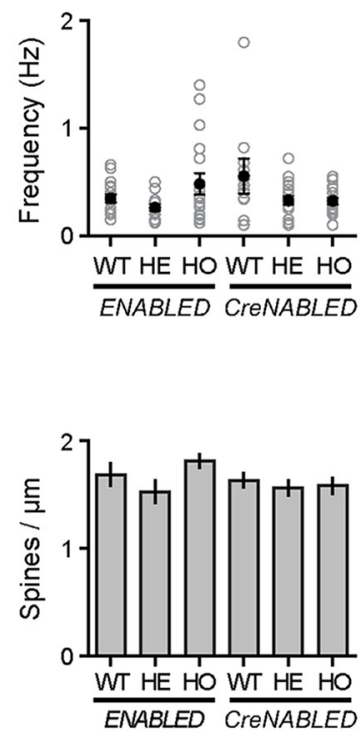

C
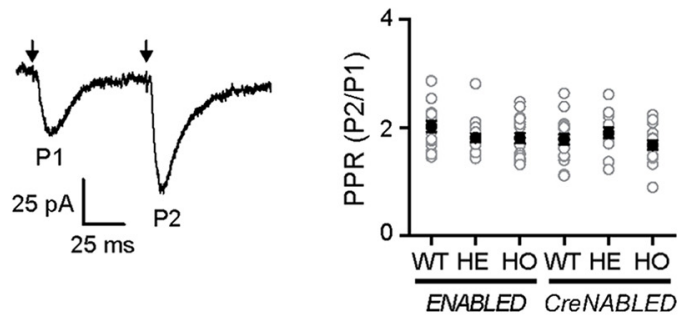

D
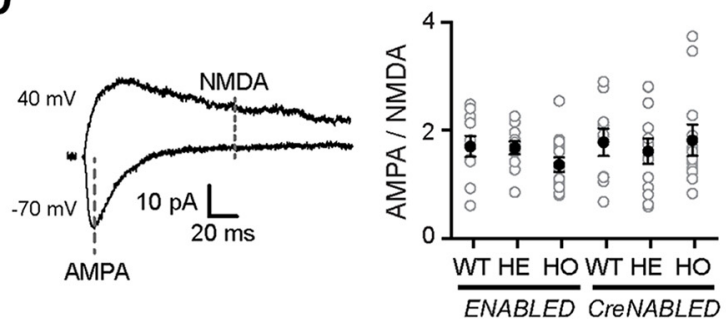

E

ENABLED

CreNABLED

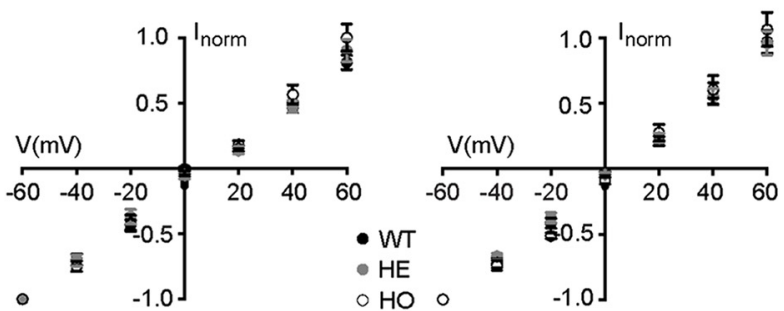

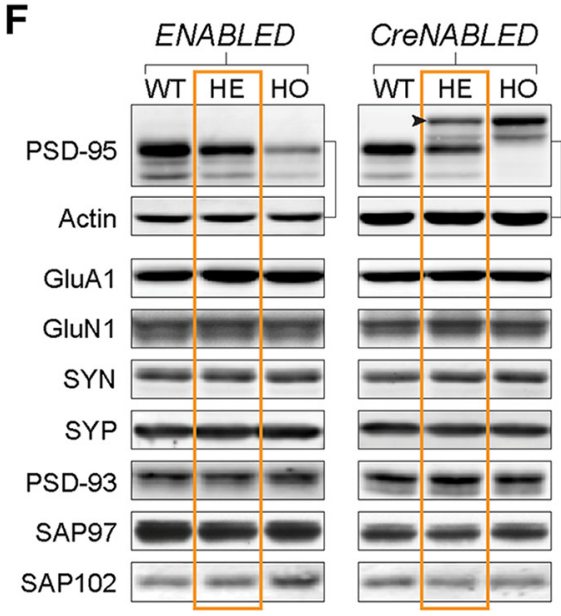

First exon $20,53 \mathrm{rd} b p$
after stop codon $\downarrow \downarrow \begin{gathered}\text { Duplicated exon } 19 \\ \text { from the begining }\end{gathered}$

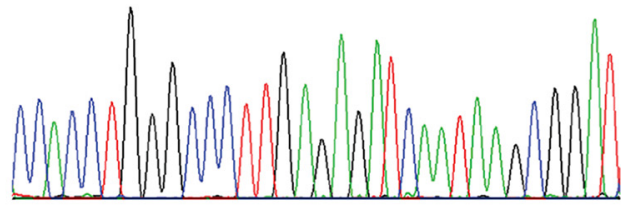

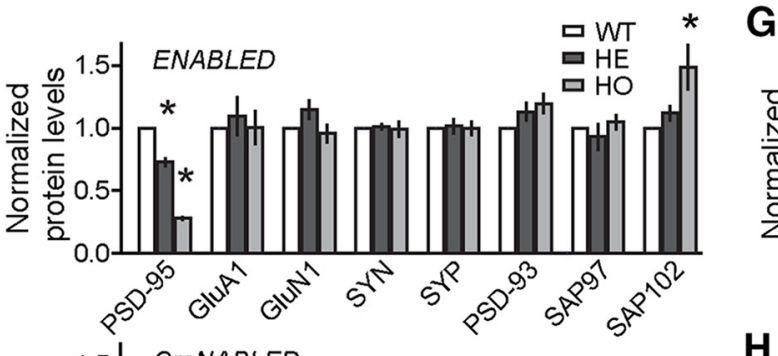
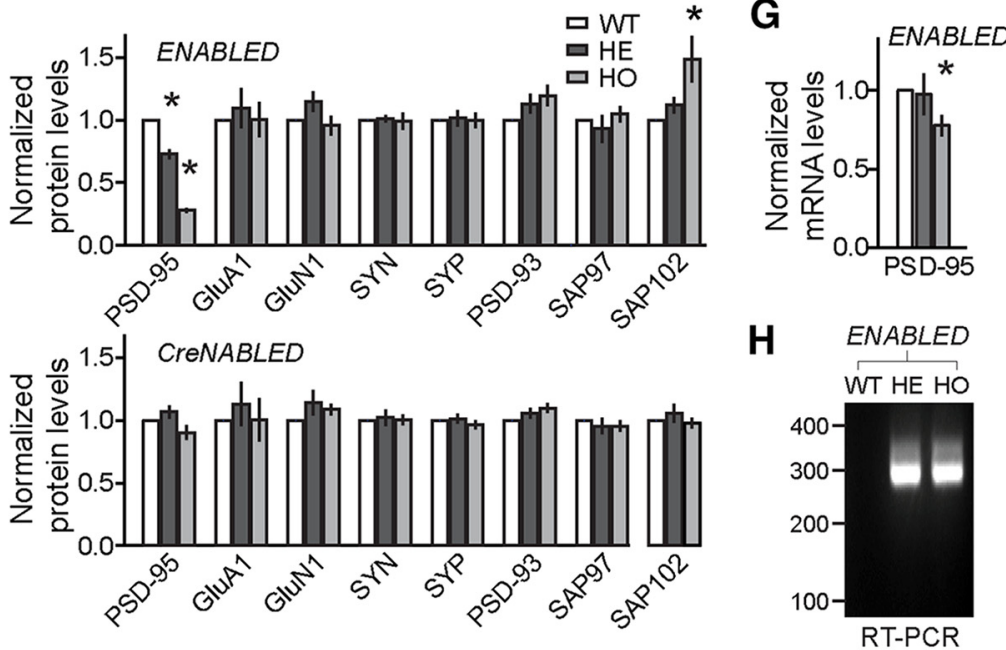

$J$

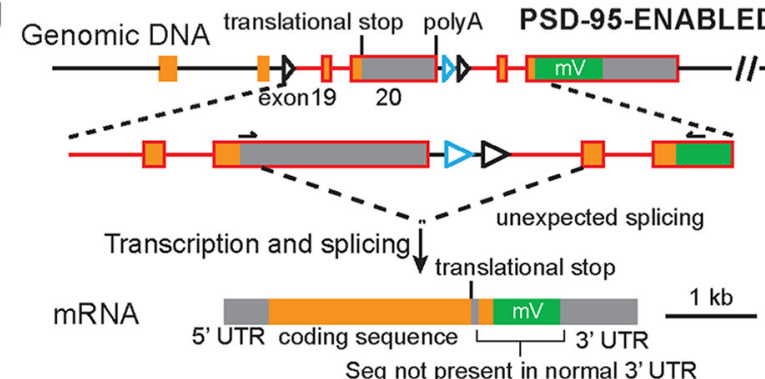


Fig. 2A3). mVenus fluorescence was not present in wild-type or PSD-95-ENABLED (i.e., before Cre recombination) samples (Fig. 2A1,A2). Relatively little fluorescence was observed in the cerebellum of global PSD-95-CreNABLED mice (Fig. 2A3), consistent with the previous findings that cerebellar Purkinje neurons do not express PSD-95 (Hunt et al., 1996; Fukaya and Watanabe, 2000). At higher-magnification under a two-photon microscope, dense green fluorescent puncta were found throughout the neuropil of the neocortex, striatum, and hippocampus (Figs. 1C3,2B). Notably, although little fluorescence was observed in the cerebellum at the macroscopic level, the pinceau termini of basket cells were found to be labeled at highmagnifications (Fig. 2B, right), consistent with previous immunohistochemical studies (Hunt et al., 1996; Fukaya and Watanabe, 2000).

In sparsely labeled hippocampal and cortical pyramidal neurons, and in striatal medium spiny neurons, PSD- $95^{\text {mVenus }}$ was highly enriched within dendritic spines with little in dendritic shafts (Figs. 1C6, 2C,D), consistent with the notion that PSD-95 is a major constituent of the PSD (Kennedy, 1997; Sheng and Hoogenraad, 2007). The PSD localization of PSD- $95^{\text {mVenus }}$ was verified by postembedding immunogold EM using an anti-GFP antibody (Fig. 1D). Nearly all gold particles $(95 \%)$ within spines resided at the PSD. In addition, we found no detectable mVenus fluorescence in cerebellar Purkinje neurons (Fig. 2C; Hunt et al., 1996; Fukaya and Watanabe, 2000). These results suggest that the labeling of PSD-95 is specific and under native expression control, and labeled PSD-95 faithfully represents endogenous PSD-95 distribution.

\footnotetext{
Figure 4. Characterizations of PSD-95-ENABLED and global CreNABLED mice. $A$, Representative traces and quantification of $\mathrm{mEPSC} S \mathrm{~s}$ recorded from CA1 neurons in acute brain slices from the indicated genotypes (10-18 cells from 3-5 mice per genotype). $\boldsymbol{B}$, Example images and quantification of spine density from CA1 hippocampal neurons labeled by DiOlistic Dil labeling; $n=15-18$ cells from five to six mice for each genotype. C, Representative EPSC traces and quantified paired pulse ratios (PPR) from CA1 pyramidal neurons evoked by two stimuli with 70 ms interstimulus interval; $n=12-18$ cells from four to six mice per genotype. $\boldsymbol{D}$, Representative EPSC traces and quantification of AMPA/NMDA receptor component ratio from CA1 pyramidal neurons. AMPA and NMDA components were measured at the indicated times at holding potentials of $-70 \mathrm{mV}$ and $+40 \mathrm{mV}$, respectively; $n=11-14$ cells from three to six animals per genotype. $E$, Average $I-V$ relationships for AMPAR-mediated EPSCs; $n=8-10$ cells from three to six animals per genotype. Experiments were conducted in the presence of $25 \mu \mathrm{m} \mathrm{D-APV}$. All data were normalized to the EPSC amplitude at $-60 \mathrm{mV}$. $\boldsymbol{F}$, Representative immunoblots (left) and quantification (right) of protein expression levels of indicated proteins from hippocampal lysates prepared from PSD-95-ENABLED and CreNABLED mice. Arrowhead indicates the primary PSD-95 ${ }^{\text {mVenus }}$ band. Actin and PSD-95 were probed from the same gel. Note that the two lower molecular weight bands in the PSD-95 blot were likely its partial degradation products or different splice isoforms because these bands also shifted to higher molecular weights in the PSD-95-CreNABLED homozygous sample in which all PSD-95 is labeled by mVenus. All bands were quantified for total PSD-95 levels. Orange boxes indicate the genotypes and their corresponding protein expression levels involved in our subsequent imaging experiments. G, qPCR quantification of PSD-95 mRNA levels using a pair of primers against exons 15 and 16 that are upstream of our genetic manipulations. Pattern coding of the bars are the same as in $\boldsymbol{F}$. $\boldsymbol{H}$, Nested RT-PCR using the primers indicated in $\boldsymbol{J}$ revealed that mVenus sequence is present in PSD-95 mRNA in the hippocampus of PSD-95-ENABLED mice. $I$, Sequencing result of the band shown in $\boldsymbol{H}$ indicating that there was splicing from $53 \mathrm{bp}$ after the stop codon of the endogenous exon 20 to the duplicated exon 19.J, Schematic illustration of the unexpected splicing leading to an mRNA with a normal open reading frame but a modified 3' UTR. This modification may explain the reduction of PSD-95 expression levels in PSD-95-ENABLED mice because $3^{\prime}$ UTR is known to be important for the mRNA trafficking and activity-dependent translation of PSD-95 (Muddashetty et al., 2011). The PCR primers used for $\boldsymbol{H}$ are also indicated. Note that our characterization cannot rule out the simultaneous production of wild-type mRNAs. * indicates statistically significant from wild-type.
}

\section{ENABLED/CreNABLED labeling of PSD-95 does not affect} synaptic plasticity or other neuronal function

Overexpression of PSD-95, the conventional way to visualize PSD-95 dynamics, is well documented for its occlusion of LTP (El-Husseini et al., 2000; Ehrlich and Malinow, 2004; Zhang and Lisman, 2010). We therefore examined whether LTP at hippocampal CA3-CA1 synapses was normal in acute slices prepared from PSD-95-ENABLED and PSD-95-CreNABLED mice. LTP was induced using a pairing protocol under whole-cell voltage-clamp configuration. The amplitudes of EPSCs were persistently potentiated to $\sim 100 \%$ above baseline for $>40 \mathrm{~min}$ after induction (Fig. 3A). No significant difference was found across wild-type, heterozygous, and homozygous genotypes for both ENABLED (wild-type, $214 \pm 37 \%$ of baseline; heterozygous, $203 \pm 29 \%, p=0.82$; cf. wild-type and homozygous, $200 \pm 21 \%$, $p=0.74$ ) and global CreNABLED (wild-type, $226 \pm 39 \%$; heterozygous, $234 \pm 28 \%, p=0.88$; and homozygous $232 \pm$ $32 \%, p=0.91$ ) neurons (Fig. $3 B$ ).

To directly compare our labeling method with conventional overexpression approaches, we used in utero electroporation to overexpress PSD- $95^{\mathrm{mVenus}}$ in a subset of neurons in homozygous global PSD-95-CreNABLED mice. Thus, in all neurons, endogenous PSD-95 was labeled by mVenus via the ENABLED strategy; and in the subset of transfected neurons, PSD-95 ${ }^{\text {mVenus }}$ was further overexpressed. The overexpression level was estimated to be $\sim 2.5$-fold above endogenous levels by comparing the PSD$95^{\mathrm{mVenus}}$ fluorescence in the overexpressing neuron with adjacent discernible PSD-95 ${ }^{\text {mVenus }}$ puncta (data not shown). The fluorescence of coelectroporated DsRed Express allowed us to identify transfected cells (Fig. 3C). Overexpression of PSD$95^{\text {mVenus }}$ completely occluded LTP $(90 \pm 15 \%$ of baseline, $p=$ 0.43); but LTP remained normal in adjacent untransfected $\mathrm{CreN}$ ABLED neurons in which PSD-95 was labeled by mVenus at endogenous levels ( $198 \pm 21 \%, p=0.016 \mathrm{cf}$. overexpressers; Fig. $3 D)$. Thus, the ENABLED strategy, unlike overexpression, does not interfere with synaptic plasticity.

PSD-95 overexpression is also known to alter many other neuronal properties. We therefore systematically examined whether our strategy prevented these alterations by measuring the frequency and amplitude of mEPSCs, spine density, pair pulse facilitation, AMPA/NMDA synaptic current ratio, and the voltage-current relationship of synaptic currents (Fig. 4A-E). No statistically significant difference was found for any of the measured parameters in both PSD-95-ENABLED and global PSD-95CreNABLED CA1 neurons across wild-type, heterozygous, and homozygous genotypes. We also determined the protein expression levels for PSD-95 and representative synaptic proteins, including other members of the PSD-95 protein family (SAP97, SAP102, and PSD-93), glutamate receptors (GluA1 and GluN1), and presynaptic proteins (synapsin and synaptophysin). After Cre recombination (i.e., $P S D$-95-CreNABLED), all protein expression was normal across genotypes (Fig. 4F). However, PSD-95 protein levels were reduced in PSD-95-ENABLED neurons (i.e., before Cre recombination; heterozygous $73 \pm 4 \%, p=$ $2.7 \times 10^{-4}$; cf. wild-type, homozygous $28 \pm 2 \%, p=3.3 \times 10^{-8}$; Fig. $4 F$ ), probably due to an unexpected splicing event that resulted in an mRNA with a normal open reading frame but a modified 3' UTR (Fig. 4G-J).

Sparsely labeled PSD-95-CreNABLED neurons and adjacent PSD-95-ENABLED neurons exhibit similar properties Although all examined functional properties of PSD-95ENABLED homozygous neurons were normal, we limited our 
A Sparse CreNABLED in an $E N A B L E D^{+/ /} / A^{+/ /-}$background

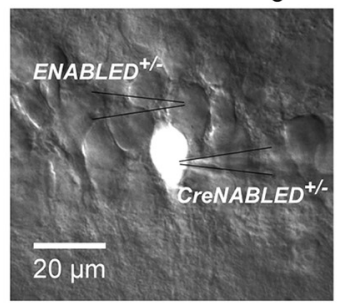

B

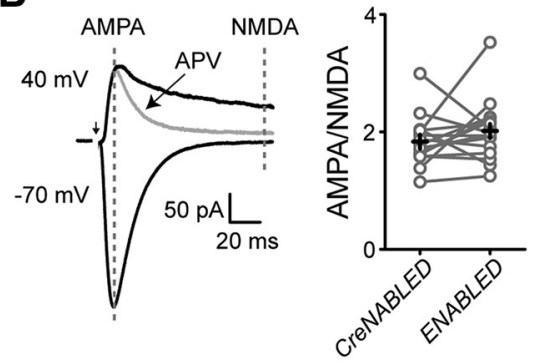

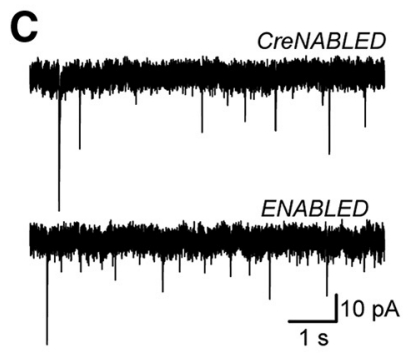

D

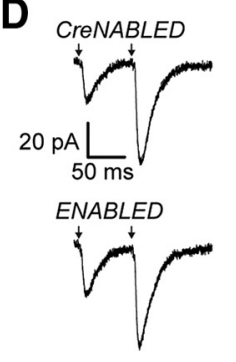

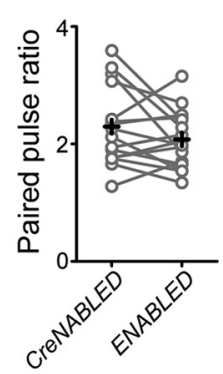
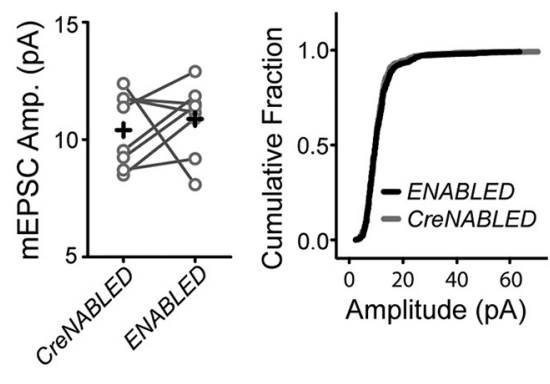

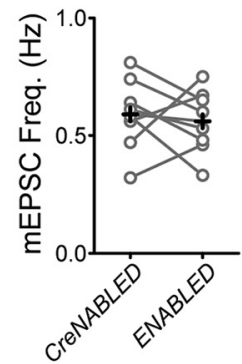

E
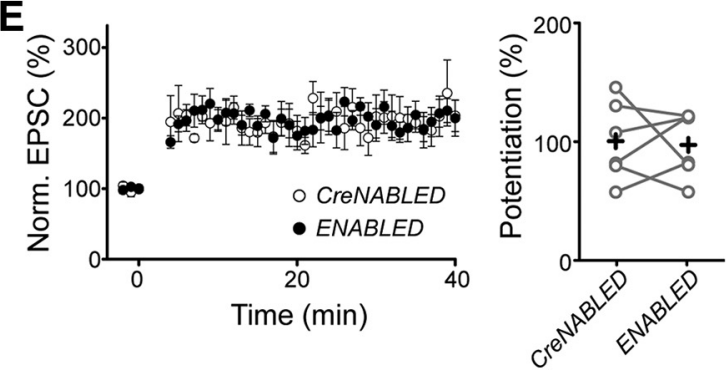

Figure 5. Comparison of the neuronal properties between PSD-95-ENABLED and sparsely labeled CreNABLED neurons within the same brain slices. $A$, Illustration of the experimental design in $\boldsymbol{B}-\boldsymbol{E}$. Cre were introduced into sparse subset of neurons in PSD-95-ENABLED/Ai9 double-heterozygous mice. The epifluorescent tdTomato image identifying the CreNABLED neurons was overlaid on a Hoffman-modulated contrast image of the brain slice. Adjacent PSD-95-ENABLED and CreNABLED neurons were sequentially recorded with alternating orders from individual brain slices to compare their synaptic properties. $\boldsymbol{B}$, Representative evoked EPSC traces (left) and pooled AMPA/NMDA receptor ratios. AMPA and NMDA components were measured at the indicated times at holding potentials of -70 and $40 \mathrm{mV}$, respectively. The NMDA response was completely abolished in the presence of $25 \mu \mathrm{m} \mathrm{D-APV} \mathrm{(gray} \mathrm{trace);} n=16$ pairs from seven animals. C, Left to right, Representative traces, amplitudes, cumulative amplitude fractions, and frequencies of mEPSCs recorded from adjacent PSD-95-CreNABLED and ENABLED neurons; $n=8$ pairs from three animals. $D$, Representative traces (left) and quantification (right) of paired pulse (70 ms interstimulus interval) EPSC traces recorded from adjacent PSD-95-CreNABLED and ENABLED CA1 pyramidal neurons (left); $n=16$ pairs from seven animals. $\boldsymbol{E}$, Averaged LTP data (left) and the percentage potentiation above baseline (right, averaged over last $10 \mathrm{~min}$ ) measured from adjacent PSD-95-CreNABLED (open circles) and ENABLED (closed circles) CA1 pyramidal neurons. Pairs were recorded sequentially from the same brain slices in alternating order; $n=6$ pairs from five animals.

experiments in the remaining of this study to heterozygous PSD95-ENABLED mice in which $\sim 75 \%$ of PSD-95 remains. Furthermore, for these experiments, Cre was introduced into a subset of neurons in the PSD-95-ENABLED heterozygous background, and therefore, labeled cells were in fact the PSD-95-CreNABLED heterozygous genotype and had normal protein expressions (Fig. $4 F)$. To verify that the neuronal properties of such sparse PSD95-CreNABLED heterozygous neurons were similar to adjacent PSD-95-ENABLED heterozygous neurons, we compared the AMPA/NMDA receptor current ratio, mEPSC frequency and amplitude, pair-pulse ratio, and LTP profile of adjacent heterozygous PSD-95-ENABLED and PSD-95-CreNABLED neurons within the same brain slices (Fig. $5 A$ ). We found no statistical significant differences in any of the measures between these two genotypes (Fig. 5B-E). Together, our results indicate that the ENABLED strategy can be used to visualize PSD-95 without overexpression side effects or alterations in synaptic function.

Subcellular distribution and dynamics of endogenous PSD-95 To demonstrate the utility of our labeling strategy, we examined the distribution and dynamics of endogenous PSD-95 in hip- pocampal CA1 neurons. It was reported that only half of AMPA receptor-mediated synaptic currents in CA1 neurons were sensitive to shRNA knockdown of PSD-95 (Elias et al., 2006). A simple explanation is that PSD-95 is present in only half of the synapses, although other possibilities remain. However, when we introduced Cre to PSD-95-ENABLED/Ai9 double-heterozygous mice by in utero viral infection, the majority of spines of CA1 neurons expressed detectable levels of PSD-95 ${ }^{\text {mVenus }}$ in the stratum radiatum (98 $\pm 1 \%$; Figs. $6 A, 1 C 6,2 C-E)$ and in the basal dendrites (data not shown). Although PSD-95 ${ }^{\text {mVenus }}$ fluorescence overall correlated with the spine tdTomato fluorescence (indicating spine volume), the $R^{2}$ value of linear fit was low $(0.54 \pm 0.08$; Fig. $6 B)$ and the mVenus to tdTomato fluorescence ratios of individual spines were highly variable (Fig. $6 C$ ), indicating that the concentration of PSD-95 is heterogeneous across spines. We confirmed that PSD-95 ${ }^{\text {mVenus }}$ in these spines was associated with sites of excitatory postsynaptic contacts using two-photon glutamate uncaging combined with perforated whole-cell voltageclamp recordings (Fig. 6D).

We next conducted FRAP experiments to examine the basal turnover of PSD-95 (Fig. 6E). There were no statistically signifi- 
A

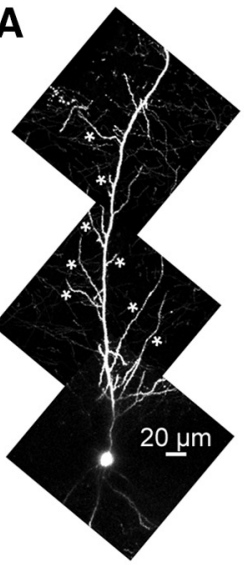

D
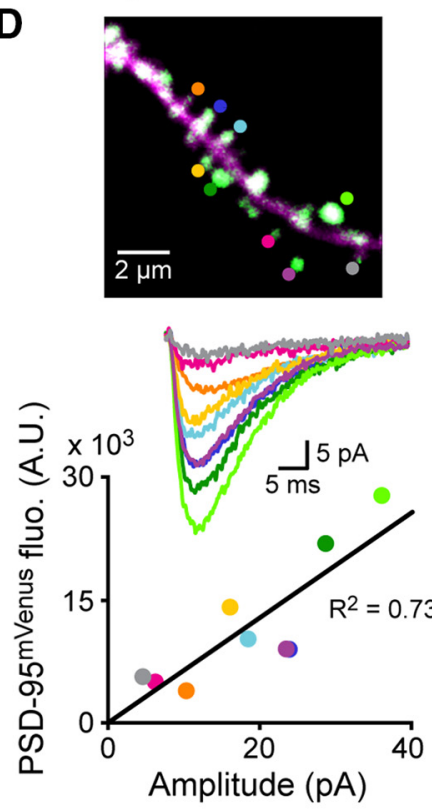

F

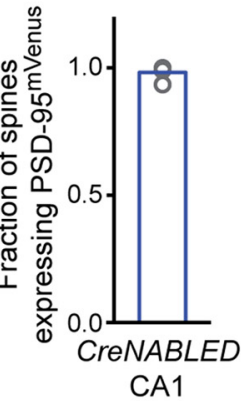

neurons
B

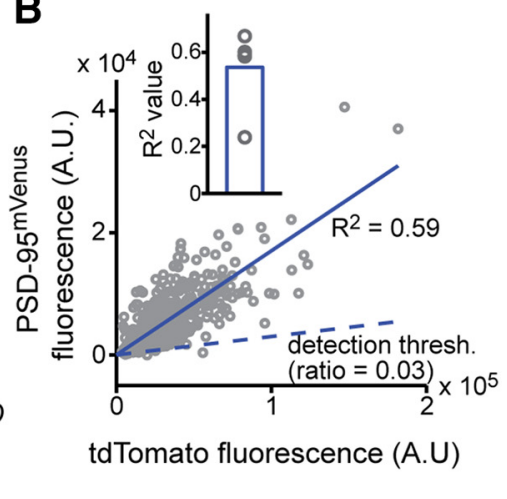

C

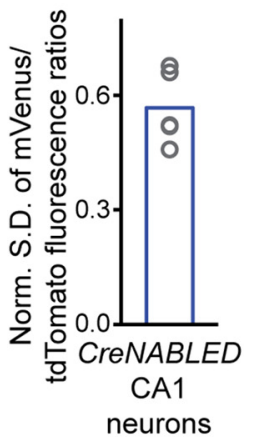

E
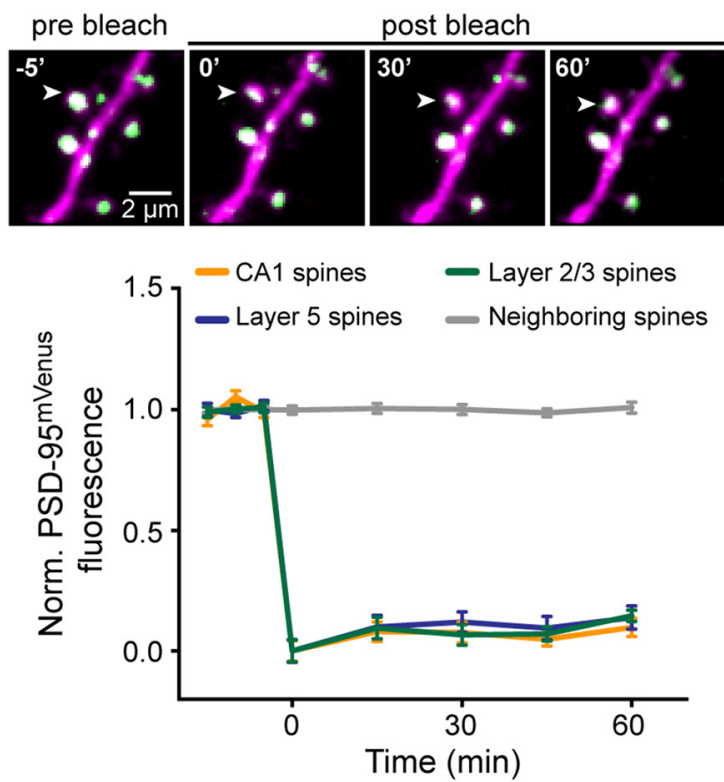

$1 \mu \mathrm{M}$ TTX

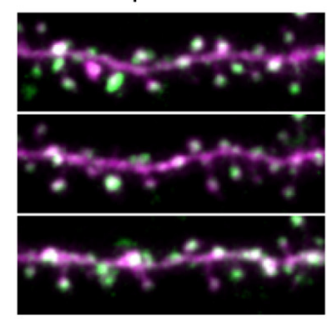

$10 \mu \mathrm{M}$ BIC

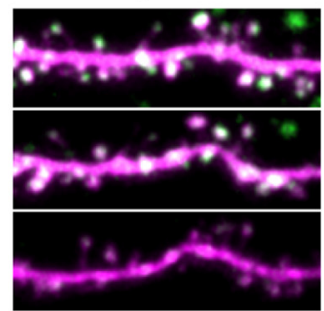

$72 \mathrm{hrs}$
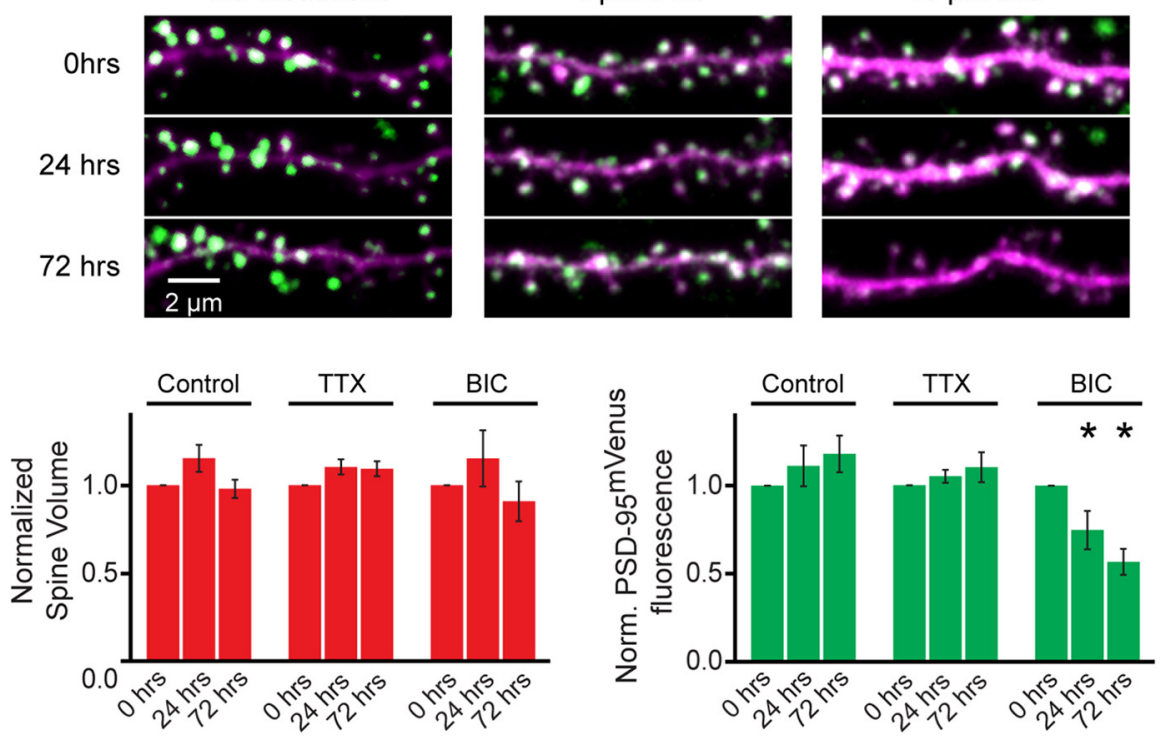

Figure 6. Subcellular distribution and dynamics of endogenous PSD-95 in pyramidal neurons. $A$, Image of a representative CA1 hippocampal neuron labeled using in utero viral infection (left) and the percentage of analyzed spines with detectable levels of PSD-95 ${ }^{\mathrm{mVenus}}$ fluorescence (right). Asterisks indicate the dendrites that were imaged and analyzed in their entirety at high-magnification; $n=5$ neurons from four animals. $\boldsymbol{B}$, Plot of tdTomato fluorescence against PSD- 95 mVenus fluorescence of individual spines. The dashed line indicates our detection threshold, corresponding to three times the SD of the tdTomato bleedthrough into the mVenus channel in individual spines. PSD-95 ${ }^{\text {mVenus }}$ fluorescence was bleedthrough corrected and the data were fit with a linear function through the coordinate origin. Inset, The $R^{2}$ values of the fit for five neurons. C, The SD of mVenus/tdTomato fluorescence ratios for all spines analyzed within a neuron (Figure legend continues.) 
cant differences in the recovery rates across spines in hippocampal CA1, cortical layer $2 / 3$, and layer 5 pyramidal neurons. On average, $\sim 10 \%$ of bleached PSD- $95^{\text {mVenus }}$ fluorescence recovered after $60 \mathrm{~min}$, suggesting that PSD-95 is highly stable. However, in 2 of 11 spines from layer 5 neurons we observed a slightly higher PSD-95 ${ }^{\mathrm{mVenus}}$ mobility (recovered to $\sim 25 \%$ in $60 \mathrm{~min}$; data not shown). This suggests a potential heterogeneity in PSD-95 dynamics at the level of individual spines. Based on the observed recovery rates, the mean turnover time of endogenous PSD-95 within spines would be on the order of $10 \mathrm{~h}$.

Because PSD-95 is stable under basal conditions, we asked whether PSD-95 content within spines could be regulated by neuronal activity. To answer this question, we chronically treated cultured hippocampal slices with TTX or bicuculline to suppress or elevate neuronal activity, respectively (Kim and Tsien, 2008; Turrigiano, 2008). The same dendritic branches of sparsely labeled CA1 neurons were imaged before treatment and again at 1 and $3 \mathrm{~d}$ post-treatment (Fig. $6 F$ ). We found that TTX treatments did not lead to any detectable change in spine volume or PSD$95^{\mathrm{mVenus}}$ abundance. However, bicuculline treatments decreased PSD-95 ${ }^{\mathrm{mVenus}}$ fluorescence within individual spines at both time points ( $68 \pm 9 \%$ of baseline at $24 \mathrm{~h}, p=0.014 ; 56 \pm 8 \%$ at $72 \mathrm{~h}$, $p=0.002$ ) without a significant change in tdTomato fluorescence, consistent with the thought that synaptic transmission was decreased under this condition. Moreover, although we did not detect a significant change in spine numbers across control and TTX treatments (data not shown), bicuculline treatment also induced a reduction in the number of spines at both time points $(82 \pm 6 \%$ of baseline at $24 \mathrm{~h}, p=0.017 ; 78 \pm 7 \%$ at $72 \mathrm{~h}, p=$ $0.025)$. These results suggest that PSD-95 levels within spines, as well as the density of spines are sensitive to elevations in neuronal activity.

\section{Visualization and examination of excitatory shaft synapses in aspiny neurons}

In addition to monitoring the distribution and dynamics of PSD-95 in pyramidal neurons, our mice allowed us to visualize the excitatory postsynaptic sites residing on the smooth dendrites of aspiny neurons, such as GABAergic interneurons (Ahmed et al., 1997; Buhl et al., 1997). Although most florescence imaging to date has focused on spiny synapses, knowledge about shaft synapses in inhibitory neurons is crucial for our understanding of the excitation/inhibition interactions and balance in the brain. However, direct functional examination of shaft synapses has been a

\footnotetext{
$\leftarrow$

(Figure legend continued.) normalized to the averaged ratio of the same neuron. $\boldsymbol{D}$, An image of a representative CA1 oblique dendrite (top), a family of uEPSCs elicited from the spines indicated in the top (middle), and uEPSC amplitudes as a function of PSD-95 ${ }^{\text {mVenus }}$ fluorescence (bottom). Colored dots indicate sites of two-photon glutamate uncaging. $\boldsymbol{E}$, Assessment of endogenous PSD-95 turnover using FRAP. An image series of a single spine (arrowhead) being bleached and monitored over time (top) and averaged recovery of PSD-95 ${ }^{\text {mVenus }}$ fluorescence (bottom) are shown;. $n=11,13$, and 11 for CA1, layer 2/3, and layer 5 pyramidal neurons, respectively; $n=35$ for neighboring unbleached control spines. $F$, Endogenous PSD-95 levels in individual spines were tuned to chronic changes in neuronal activity. Representative image series of the same dendritic segments monitored over $3 \mathrm{~d}$ with the indicated treatment (top) and normalized spine volume (red) and PSD-95 ${ }^{\text {menus }}$ fluorescence (green) at the indicated time points (bottom) are shown; $n=7$ cells from 4 slices, nine cells from five slices, and seven cells from four slices for untreated, TTX, and bicuculline (BIC) conditions, respectively. Signals from 10 to 80 spines were averaged for each cell, and each condition included a total of 370 625 spines. All data were normalized to baseline values before averaging. * indicates statistically significant from untreated controls.
}

major challenge due to the lack of distinct morphological features such as dendritic spines.

When in utero viral infection was used, we were able to routinely find cortical, cerebellar and hippocampal aspiny neurons with PSD-95 ${ }^{\mathrm{mVenus}}$ puncta along their dendritic shafts (Fig. 7A; representing $\sim 15 \%$ of all labeled neurons). These PSD- $95^{\text {mVenus }}$ puncta were verified to be bonafide synapses using two-photon glutamate uncaging combined with whole-cell recording (Fig. $7 B$ ). The uEPSCs positively correlated with the amount of PSD-95 ${ }^{\text {mVenus }}$ fluorescence at a given site. Importantly, glutamate uncaging at dendritic sites lacking PSD- $95^{\text {mVenus }}$ fluorescence resulted in minimal or no responses (Fig. $7 B$ ). These results indicate that our PSD-95-ENABLED mice provides an entry point for visualizing and examining individual excitatory shaft synapses in aspiny neurons.

Given that shaft synapses lack distinct morphological compartments, we examined whether the turnover of PSD-95 would be increased at these synaptic sites. We conducted FRAP experiments, and found, surprisingly, that the recovery rate of PSD-95 ${ }^{\text {mVenus }}$ fluorescence at shaft synapses was very similar to that observed within dendritic spines (Fig. 7C). These data indicate that the basal dynamics of endogenous PSD-95 does not depend on the synaptic compartment (i.e., spine vs dendrite) or the neuronal type. This result implies that the mechanisms governing molecular exchange between the postsynaptic density and parental dendrites are similar between shaft and spiny synapses.

To directly analyze excitatory shaft synapses in specific neuronal subtypes, we crossed PSD-95-ENABLED/Ai9 mice to $P V$ IRES-Cre mice, in which Cre expression is limited to only the fast-spiking PV-positive interneurons (Fig. 7D). The identity of labeled neurons was confirmed as fast spiking using whole-cell current injections (Fig. 7E). Two-photon glutamate uncaging evoked uEPSCs that exhibited similar amplitude and kinetic properties of spontaneous mEPSCs (Fig. $7 F, G$ ). These uEPSCs were completely blocked by the AMPA receptor blocker NBQX. Importantly, uncaging at dendritic sites without PSD-95 ${ }^{\text {menus }}$ fluorescence produced little to no response (Fig. $7 G$, positions 2 and 4). The turnover rate of PSD-95 in these neurons closely matched the recovery rates observed in excitatory neuronal types (Fig. 7C), suggesting that basal PSD-95 turnover is highly conserved across neuronal subtypes.

We also labeled PSD-95 within synapses of dopaminergic neurons by crossing our PSD-95-ENABLED mice to DAT-Cre mice (Fig. 7H). These labeled neurons were likely dopaminergic neurons as they expressed a characteristic hyperpolarizationactivated current $\left(\mathrm{I}_{\mathrm{h}}\right)$ (Mercuri et al., 1995) (Fig. 7I). Similar to PV-positive neurons, two-photon induced uncaging of glutamate only elicited uEPSCs when juxtaposed to PSD-95 mVenus puncta (Fig. 7J). Bath application of NBQX completely abolished the uEPSCs indicating that they were mediated by postsynaptic AMPA receptors. Together our data demonstrate that the PSD95-ENABLED mice can be used to visualize and analyze excitatory shaft synapses in specific aspiny neuronal types in live cells, which was previously unattainable.

\section{Discussion}

We present ENABLED—a mouse conditional knock-in strategy for the fluorescent tagging of endogenous proteins for live cell imaging. We used this strategy to label PSD-95 with mVenus and monitor, for the first time, the basal and activity-dependent dynamics of endogenous PSD-95 without perturbations in neuronal properties. Our mouse line also permitted the live exami- 
A
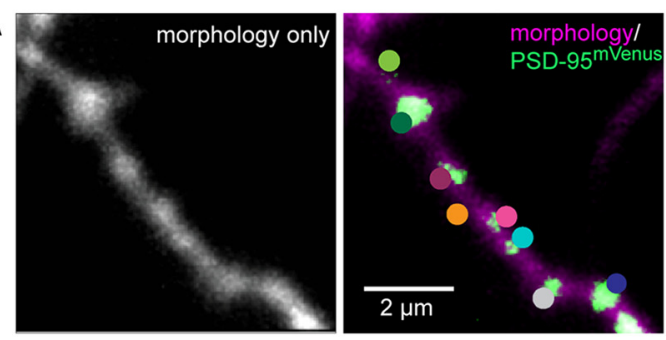

B
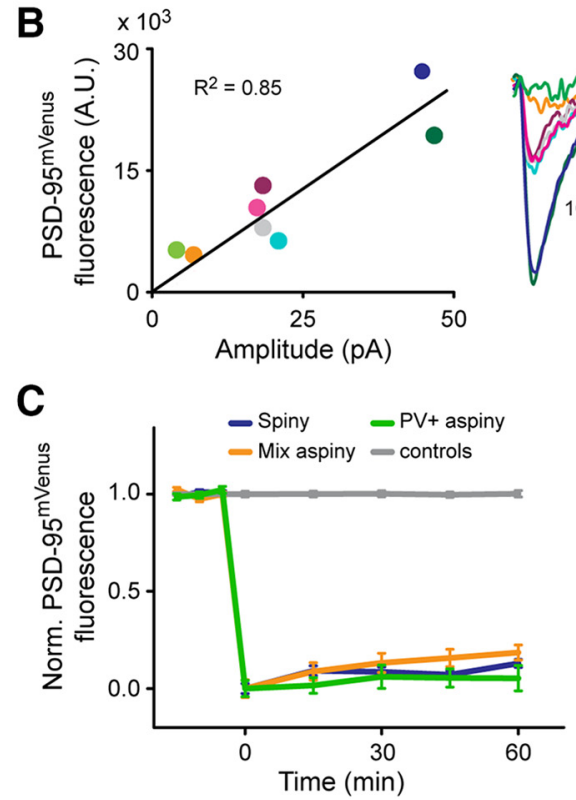
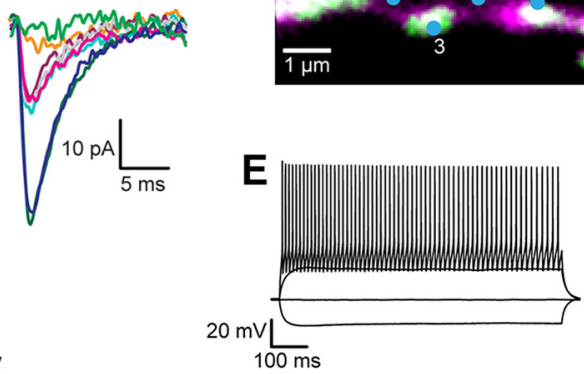

$\mathbf{F}$

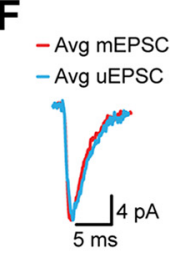

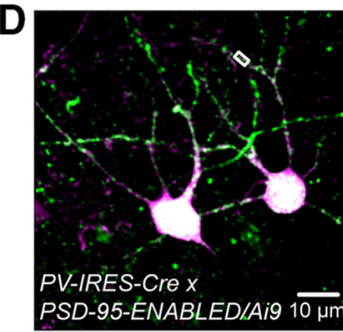

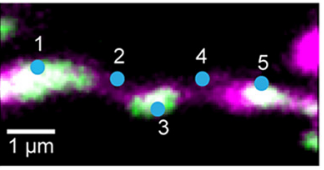

G

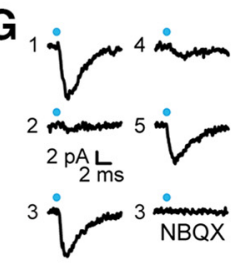

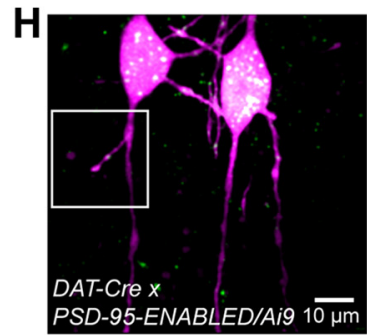
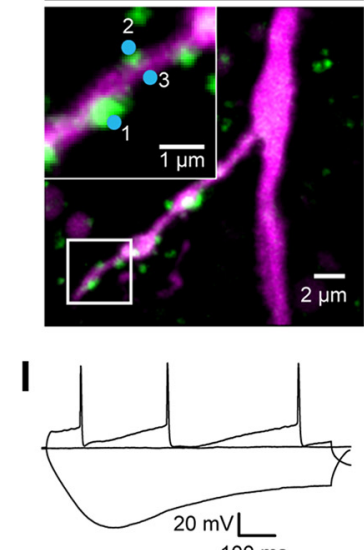

$\mathbf{J}$

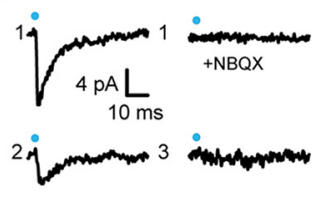

Figure 7. Visualization and characterization of excitatory shaft synapses on aspiny neurons. $A$, Representative images of the morphology (left) and morphology overlaid with PSD-95 ${ }^{\mathrm{mVenus}}$ fluorescence (right) of a dendritic branch from a cortical aspiny neuron labeled by in utero viral infection. Colored dots indicate sites of two-photon glutamate uncaging characterized in $\boldsymbol{B}$. $\boldsymbol{B}$, uEPSC amplitudes are plotted on the left as a function of PSD-95 ${ }^{\text {mVenus }}$ fluorescence and fit with a linear function. Colors correspond to the uncaging location shown in $A$, and uEPSCs are shown on the right (average of 5 trials). C, Assessment of endogenous PSD-95 turnover in aspiny neurons using FRAP; $n=10$ for PV-positive neurons, 18 for mixed cortical aspiny neurons, 35 for all spiny neurons shown in Figure 4D, and 59 for all unbleached controls. D, Representative PV-positive neurons from a PV-IRES-Cre/PSD-95-ENABLED/Ai9 triple-heterozygous mouse. Blue dots in the high-magnification image show sites of two-photon glutamate uncaging. $\boldsymbol{E}$, Current-clamp recordings in response to current injection confirmed that the right labeled cell in $\boldsymbol{D}$ was a fast spiking interneuron. $\boldsymbol{F}, 0$ verlaid average $\mathrm{mEPSC}$ and uEPSC recorded from the PV-positive neuron shown in $\boldsymbol{D}$ without normalization. $\boldsymbol{G}$, Average uEPSCs evoked at the dendritic locations indicated in $\boldsymbol{D}$. $\boldsymbol{H}$, Representative VTA dopaminergic neurons from a DAT-Cre/PSD-95-ENABLED/Aig triple-heterozygous mouse. Zoom-in shows the dendritic segment that underwent two-photon glutamate uncaging stimulation at the positions indicated (blue dots). $I$, Current-clamp recordings in response to current injection showing the action potential shape and $I$, response characteristic for dopaminergic neurons. $J$, Average uEPSCs evoked at the locations indicated in $\boldsymbol{H}$.

nation of the otherwise-unidentifiable excitatory shaft synapses in aspiny neurons.

The ENABLED strategy represents the first employment of exon duplication to fluorescently label proteins. Two previously published studies have attempted exon duplication to knock in point mutations (Bayascas et al., 2006; Skvorak et al., 2006). However, the effort was aborted in one study (Bayascas et al., 2006), whereas there was no functional characterization in the other (Skvorak et al., 2006). Thus, until the present study, it remained unknown whether exon duplication is a practical method to fluorescently label proteins.

The ENABLED strategy has significant advantages over existing fluorescent labeling methods. Compared with conventional FP tagging, it avoids the caveats associated with overexpression. Compared with a standard knock-in approach, ENABLED is amendable to labeling a protein in all cells for population characterization, a sparse subset of cells for high-contrast single-cell or single-synapse imaging, or in selected cell types for subtype specific analysis. Compared with immunolabeling methods, ENABLED does not suffer potential nonspecificity, and provides the possibility of live imaging and cell-specific high-contrast in tissue. Importantly, a major advantage of the ENABLED strategy is that the labeling is stoichiometric. This property in combination with appropriate calibration methods may allow for future quantification of protein abundance at individual synapses, and the determination of protein stoichiometry when ENABLED is applied to multiple proteins.

A recently developed approach uses expressed FP-tagged intrabodies (i.e., recombinant single-chain antibodies) to label specific proteins in living cells (Nizak et al., 2003a, b; Fukata et al., 2013; Gross et al., 2013). However, this method requires intrabody expression levels precisely matching the levels of target proteins: excess intrabody would mislocalize and underexpression would bias labeling to near intrabody production sites. Although this problem can be alleviated by feedback transcriptional controls (Gross et al., 2013), these controls still require excess intrabodies. It is also unknown whether this type of transcriptional regulation is capable of following acute protein translation of preexisting mRNAs at dendritic locations far away from the nucleus (Bramham and Wells, 2007). In addition, the intrabody and transcriptional regulatory domains add significant size to the FP, which may reduce its accessibility to substrates in densely packed 
structures such as the PSD. In contrast, our strategy precisely follows native transcriptional and translational controls and does not suffer from problems associated with potential imbalanced abundance between the intrabody and the target protein. The smaller size of FP tags also imposes less spatial constraints and allows for higher potential labeling density in the PSD compared with immunolabeling and intrabody methods.

In PSD-95-ENABLED mice, PSD-95 levels were reduced possibly due to an unexpected splicing involving the duplicated exons. In the current study, we circumvented this complication by performing experiments in heterozygous mice in which most ( $\sim 75 \%)$ PSD-95 remains. Indeed, in contrast to overexpression, all tested neuronal functions of $P S D-95-E N A B L E D$ neurons were normal and indistinguishable from wild-type or PSD-95CreNALBED neurons (Fig. 3-5). It should also be noted that all imaged neurons were of the CreNABLED genotype in which PSD-95 expression is normal (Fig. $4 F$ ). The unexpected splicing may be eliminated in future ENABLED efforts by implementing a strong transcriptional stop, such as the SV40 transcriptional stop (Madisen et al., 2010) between the endogenous and duplicated copies of exon(s).

Although generating a knock-in mouse is relatively costly and time consuming, the production cost and time have greatly decreased in the past few decades thanks to the continuous development of innovative mouse genetic technologies such as the recombineering (Liu et al., 2003) and the CRISPR technologies (Sander and Joung, 2014). Furthermore, the simple design and standardizable feature of the ENABLED strategy may allow for systematic, and thus, cost-effective efforts to tag a large number of synaptic proteins that have been previously C-terminally FP-tagged, albeit using overexpression methods (e.g., CaMKII, PSD-93, Ras, Rho, Cdc42, PKA, GKAP, Homer, bassoon, synaptobrevin, and synaptophysin). Currently, our strategy cannot label proteins that require $\mathrm{N}$-terminal tagging because a simple duplication of the first coding exon could cause undesired splicing events. For N-terminal labeling, further methodological development will be required.

Although FP-tagging is widely used in overexpression studies, it remains a legitimate concern whether the FP-tagged protein is functionally equivalent to its endogenous counterpart. Our study presents the first conclusive evidence that PSD-95 ${ }^{\text {mVenus }}$ is functionally equivalent to wild-type PSD-95 because all tested neuronal functions and protein expression levels appeared normal even after all PSD-95 was replaced by PSD-95 ${ }^{\text {mVenus }}$ in PSD-95-CreNABLED homozygous neurons (Figs. 3, 4). On the other hand, this conclusion should not be extended to tagging of PSD-95 with significantly larger tags because they may potentially suffer geometric constraints in the densely packed PSD.

The majority of dendritic spines (98\%) in CA1 hippocampal neurons expressed detectable levels of PSD-95. This appears in contrast to a previous study involving shRNA knockdown of PSD-95 and PSD-93, which suggested that PSD-95 may be important for AMPA receptor-mediated synaptic transmission only in half of CA1 synapses (Elias et al., 2006). However, our quantification also indicates that PSD-95 content is highly heterogeneous across individual spines. It is possible that quantitative heterogeneity in PSD-95 expression (i.e., differences in PSD-95 expression levels within individual spines that are above or below a certain threshold) leads to qualitative differences in AMPA receptor trafficking and synaptic transmission.

The turnover rate of endogenous PSD-95 was very low $(\sim 10 \%$ over $60 \mathrm{~min})$ and was independent of neuronal type or postsynaptic compartment (i.e., spine versus shaft synapses). This mobility is comparable, yet slightly less than what has been observed using overexpression (Okabe et al., 2001; Gray et al., 2006; Yoshii and Constantine-Paton, 2007; Steiner et al., 2008; Sturgill et al., 2009). However, although PSD-95 is stable under basal conditions, its levels in spines of CA1 neurons in cultured hippocampal slices decreased over days when neuronal activity was elevated using bicuculline. This result is consistent with Sun and Turrigiano (2011)) but opposite to Ehlers (2003). The difference may be due to different culture conditions and/or different brain regions [Sun and Turrigiano (2011) used dissociated primary cultures of cortical neurons; Ehlers (2003) used primary hippocampal cultures with mixed neuronal populations; whereas we focused only on CA1 neurons in organotypic hippocampal slices]. Compared with these previous studies, our study may also be more sensitive in PSD-95 dynamics because our labeling strategy allows for longitudinal examination of endogenous protein expression and dynamics of the same dendritic branch within individual neurons. We found minimal changes in PSD-95 content when we chronically blocked action potentials in hippocampal slices using TTX. Because AMPA receptor content is thought to increase at the synapse under this condition, our results suggest that an increase in PSD-95 content may not be a prerequisite for synaptic potentiation and is consistent with previous studies (Okabe et al., 2001; Steiner et al., 2008; Sturgill et al., 2009).

Another major advantage of the PSD-95-ENABLED mouse lies in its ability to mark excitatory shaft synapses in aspiny interneurons. These synapses are the primary drive of the function of interneurons. However, many fundamental questions regarding the structure and function of shaft synapses remain unclear because they lack distinct morphological features, and are thus difficult to identify unambiguously. We present evidence that shaft synapses in specific subtypes of neurons can be identified and individually activated using two-photon glutamate uncaging (Fig. 7). The ability to visualize and manipulate individual excitatory shaft synapses in specific neuronal types will open the door for future research regarding the development, distribution, function, plasticity, and signaling dynamics of individual excitatory shaft synapses.

The PSD-95-ENABLED mouse can be used for many other research directions. For example, this mouse allows for an investigation of endogenous PSD-95 distribution as a function of dendritic location, which may provide insights into the organization principle of synapses within a neuron (Spruston, 2008; Branco and Hausser, 2011; Piskorowski and Chevaleyre, 2012). In addition, cell-type-specific Cre-driver lines combined with immunoprecipitation of PSD-95 ${ }^{\text {mVenus }}$ containing synaptic complexes using available anti-GFP antibodies may allow for cell-type-specific proteomic studies of the synaptic composition.

\section{References}

Ahmed B, Anderson JC, Martin KA, Nelson JC (1997) Map of the synapses onto layer 4 basket cells of the primary visual cortex of the cat. J Comp Neurol 380:230-242. CrossRef Medline

Badea TC, Hua ZL, Smallwood PM, Williams J, Rotolo T, Ye X, Nathans J (2009) New mouse lines for the analysis of neuronal morphology using CreER(T)/loxP-directed sparse labeling. PLoS One 4:e7859. CrossRef Medline

Bayascas JR, Sakamoto K, Armit L, Arthur JS, Alessi DR (2006) Evaluation of approaches to generation of tissue-specific knock-in mice. J Biol Chem 281:28772-28781. CrossRef Medline

Béïque JC, Andrade R (2003) PSD-95 regulates synaptic transmission 
and plasticity in rat cerebral cortex. J Physiol 546:859-867. CrossRef Medline

Bergmann I, Nitsch R, Frotscher M (1991) Area-specific morphological and neurochemical maturation of nonpyramidal neurons in the rat hippocampus as revealed by parvalbumin immunocytochemistry. Anat Embryol (Berl) 184:403-409. CrossRef Medline

Bischofberger J, Engel D, Li L, Geiger JR, Jonas P (2006) Patch-clamp recording from mossy fiber terminals in hippocampal slices. Nat Protoc 1:2075-2081. CrossRef Medline

Bramham CR, Wells DG (2007) Dendritic mRNA: transport, translation and function. Nat Rev Neurosci 8:776-789. CrossRef Medline

Branco T, Häusser M (2011) Synaptic integration gradients in single cortical pyramidal cell dendrites. Neuron 69:885-892. CrossRef Medline

Buhl EH, Tamás G, Szilágyi T, Stricker C, Paulsen O, Somogyi P (1997) Effect, number and location of synapses made by single pyramidal cells onto aspiny interneurones of cat visual cortex. J Physiol 500:689-713. Medline

Chalfie M, Tu Y, Euskirchen G, Ward WW, Prasher DC (1994) Green fluorescent protein as a marker for gene expression. Science 263:802-805. CrossRef Medline

Cubitt AB, Heim R, Adams SR, Boyd AE, Gross LA, Tsien RY (1995) Understanding, improving and using green fluorescent proteins. Trends Biochem Sci 20:448-455. CrossRef Medline

Ehlers MD (2003) Activity level controls postsynaptic composition and signaling via the ubiquitin-proteasome system. Nat Neurosci 6:231-242. CrossRef Medline

Ehrlich I, Malinow R (2004) Postsynaptic density 95 controls AMPA receptor incorporation during long-term potentiation and experience-driven synaptic plasticity. J Neurosci 24:916-927. CrossRef Medline

El-Husseini AE, Schnell E, Chetkovich DM, Nicoll RA, Bredt DS (2000) PSD-95 involvement in maturation of excitatory synapses. Science 290: 1364-1368. CrossRef Medline

Elias GM, Funke L, Stein V, Grant SG, Bredt DS, Nicoll RA (2006) Synapsespecific and developmentally regulated targeting of AMPA receptors by a family of MAGUK scaffolding proteins. Neuron 52:307-320. CrossRef Medline

Fukata Y, Dimitrov A, Boncompain G, Vielemeyer O, Perez F, Fukata M (2013) Local palmitoylation cycles define activity-regulated postsynaptic subdomains. J Cell Biol 202:145-161. CrossRef Medline

Fukaya M, Watanabe M (2000) Improved immunohistochemical detection of postsynaptically located PSD-95/SAP90 protein family by protease section pretreatment: a study in the adult mouse brain. J Comp Neurol 426:572-586. CrossRef Medline

Futai K, Kim MJ, Hashikawa T, Scheiffele P, Sheng M, Hayashi Y (2007) Retrograde modulation of presynaptic release probability through signaling mediated by PSD-95-neuroligin. Nat Neurosci 10:186-195. CrossRef Medline

Gan WB, Grutzendler J, Wong WT, Wong RO, Lichtman JW (2000) Multicolor "DiOlistic" labeling of the nervous system using lipophilic dye combinations. Neuron 27:219-225. CrossRef Medline

Gray NW, Weimer RM, Bureau I, Svoboda K (2006) Rapid redistribution of synaptic PSD-95 in the neocortex in vivo. PLoS Biol 4:e370. CrossRef Medline

Griesbeck O, Baird GS, Campbell RE, Zacharias DA, Tsien RY (2001) Reducing the environmental sensitivity of yellow fluorescent protein: mechanism and applications. J Biol Chem 276:29188-29194. CrossRef Medline

Gross GG, Junge JA, Mora RJ, Kwon HB, Olson CA, Takahashi TT, Liman ER, Ellis-Davies GC, McGee AW, Sabatini BL, Roberts RW, Arnold DB (2013) Recombinant probes for visualizing endogenous synaptic proteins in living neurons. Neuron 78:971-985. CrossRef Medline

Herzog E, Nadrigny F, Silm K, Biesemann C, Helling I, Bersot T, Steffens H, Schwartzmann R, Nägerl UV, El Mestikawy S, Rhee J, Kirchhoff F, Brose $\mathrm{N}$ (2011) In vivo imaging of intersynaptic vesicle exchange using VGLUT1 Venus knock-in mice. J Neurosci 31:15544-15559. CrossRef Medline

Hunt CA, Schenker LJ, Kennedy MB (1996) PSD-95 is associated with the postsynaptic density and not with the presynaptic membrane at forebrain synapses. J Neurosci 16:1380-1388. Medline

Kennedy MB (1997) The postsynaptic density at glutamatergic synapses. Trends Neurosci 20:264-268. CrossRef Medline
Kim E, Sheng M (2004) PDZ domain proteins of synapses. Nat Rev Neurosci 5:771-781. CrossRef Medline

Kim J, Tsien RW (2008) Synapse-specific adaptations to inactivity in hippocampal circuits achieve homeostatic gain control while dampening network reverberation. Neuron 58:925-937. CrossRef Medline

Liu P, Jenkins NA, Copeland NG (2003) A highly efficient recombineeringbased method for generating conditional knockout mutations. Genome Res 13:476-484. CrossRef Medline

Madisen L, Zwingman TA, Sunkin SM, Oh SW, Zariwala HA, Gu H, Ng LL, Palmiter RD, Hawrylycz MJ, Jones AR, Lein ES, Zeng H (2010) A robust and high-throughput Cre reporting and characterization system for the whole mouse brain. Nat Neurosci 13:133-140. CrossRef Medline

Mercuri NB, Bonci A, Calabresi P, Stefani A, Bernardi G (1995) Properties of the hyperpolarization-activated cation current Ih in rat midbrain dopaminergic neurons. Eur J Neurosci 7:462-469. CrossRef Medline

Muddashetty RS, Nalavadi VC, Gross C, Yao X, Xing L, Laur O, Warren ST, Bassell GJ (2011) Reversible inhibition of PSD-95 mRNA translation by miR-125a, FMRP phosphorylation, and mGluR signaling. Mol Cell 42: 673-688. CrossRef Medline

Nagai T, Ibata K, Park ES, Kubota M, Mikoshiba K, Miyawaki A (2002) A variant of yellow fluorescent protein with fast and efficient maturation for cell-biological applications. Nat Biotechnol 20:87-90. CrossRef Medline

Nitsch R, Bergmann I, Küppers K, Mueller G, Frotscher M (1990) Late appearance of parvalbumin-immunoreactivity in the development of GABAergic neurons in the rat hippocampus. Neurosci Lett 118:147-150. CrossRef Medline

Nizak C, Monier S, del Nery E, Moutel S, Goud B, Perez F (2003a) Recombinant antibodies to the small GTPase Rab6 as conformation sensors. Science 300:984-987. CrossRef Medline

Nizak C, Martin-Lluesma S, Moutel S, Roux A, Kreis TE, Goud B, Perez F (2003b) Recombinant antibodies against subcellular fractions used to track endogenous Golgi protein dynamics in vivo. Traffic 4:739-753. CrossRef Medline

Okabe S, Urushido T, Konno D, Okado H, Sobue K (2001) Rapid redistribution of the postsynaptic density protein PSD-Zip45 (Homer 1c) and its differential regulation by NMDA receptors and calcium channels. J Neurosci 21:9561-9571. Medline

Piskorowski RA, Chevaleyre V (2012) Synaptic integration by different dendritic compartments of hippocampal CA1 and CA2 pyramidal neurons. Cell Mol Life Sci 69:75-88. CrossRef Medline

Pologruto TA, Sabatini BL, Svoboda K (2003) ScanImage: flexible software for operating laser scanning microscopes. Biomed Eng Online 2:13. CrossRef Medline

Prelich G (2012) Gene overexpression: uses, mechanisms, and interpretation. Genetics 190:841-854. CrossRef Medline

Rah JC, Bas E, Colonell J, Mishchenko Y, Karsh B, Fetter RD, Myers EW, Chklovskii DB, Svoboda K, Harris TD, Isaac JT (2013) Thalamocortical input onto layer 5 pyramidal neurons measured using quantitative large-scale array tomography. Front Neural Circuits 7:177. CrossRef Medline

Rak A, Pylypenko O, Durek T, Watzke A, Kushnir S, Brunsveld L, Waldmann H, Goody RS, Alexandrov K (2003) Structure of Rab GDP-dissociation inhibitor in complex with prenylated YPT1 GTPase. Science 302:646650. CrossRef Medline

Sander JD, Joung JK (2014) CRISPR-Cas systems for editing, regulating and targeting genomes. Nat Biotechnol 32:347-355. CrossRef Medline

Sheng M, Hoogenraad CC (2007) The postsynaptic architecture of excitatory synapses: a more quantitative view. Annu Rev Biochem 76:823-847. CrossRef Medline

Skvorak K, Vissel B, Homanics GE (2006) Production of conditional point mutant knockin mice. Genesis 44:345-353. CrossRef Medline

Spruston N (2008) Pyramidal neurons: dendritic structure and synaptic integration. Nat Rev Neurosci 9:206-221. CrossRef Medline

Stein V, House DR, Bredt DS, Nicoll RA (2003) Postsynaptic density-95 mimics and occludes hippocampal long-term potentiation and enhances long-term depression. J Neurosci 23:5503-5506. Medline

Steiner P, Higley MJ, Xu W, Czervionke BL, Malenka RC, Sabatini BL (2008) Destabilization of the postsynaptic density by PSD-95 serine 73 phos- 
phorylation inhibits spine growth and synaptic plasticity. Neuron 60: 788-802. CrossRef Medline

Sturgill JF, Steiner P, Czervionke BL, Sabatini BL (2009) Distinct domains within PSD-95 mediate synaptic incorporation, stabilization, and activity-dependent trafficking. J Neurosci 29:12845-12854. CrossRef Medline

Sun Q, Turrigiano GG (2011) PSD-95 and PSD-93 play critical but distinct roles in synaptic scaling up and down. J Neurosci 31:6800-6808. CrossRef Medline

Turrigiano GG (2008) The self-tuning neuron: synaptic scaling of excitatory synapses. Cell 135:422-435. CrossRef Medline

Wagner S, Bader ML, Drew D, de Gier JW (2006) Rationalizing membrane protein overexpression. Trends Biotechnol 24:364-371. CrossRef Medline
Yoshii A, Constantine-Paton M (2007) BDNF induces transport of PSD-95 to dendrites through PI3K-AKT signaling after NMDA receptor activation. Nat Neurosci 10:702-711. CrossRef Medline

Zhang J, Xu TX, Hallett PJ, Watanabe M, Grant SG, Isacson O, Yao WD (2009) PSD-95 uncouples dopamine-glutamate interaction in the D1/ PSD-95/NMDA receptor complex. J Neurosci 29:2948-2960. CrossRef Medline

Zhang P, Lisman JE (2012) Activity-dependent regulation of synaptic strength by PSD-95 in CA1 neurons. J Neurophysiol 107:1058-1066. CrossRef Medline

Zhong H, Sia GM, Sato TR, Gray NW, Mao T, Khuchua Z, Huganir RL, Svoboda K (2009) Subcellular dynamics of type II PKA in neurons. Neuron 62:363-374. CrossRef Medline 